\title{
Phylogenetic and population genetic analyses of Phaeosphaeria nodorum and its close relatives indicate cryptic species and an origin in the Fertile Crescent
}

\author{
Megan C. McDonald ${ }^{\mathrm{a}, *}$, Mohammad Razavi ${ }^{\mathrm{b}}$, Timothy L. Friesen ${ }^{\mathrm{c}}$, Patrick C. Brunner ${ }^{\mathrm{a}}$, \\ Bruce A. McDonald ${ }^{\text {a }}$ \\ a Plant Pathology Group, Institute of Integrative Biology, ETH Zurich, CH-8092 Zürich, Switzerland \\ ${ }^{\mathrm{b}}$ Department of Plant Pathology, Iranian Research Institute of Plant Protection, 19395-1454 Tehran, Iran \\ ${ }^{\mathrm{c}}$ United States Department of Agriculture, Agriculture Research Service, Cereal Crops Research Unit, Northern Crop Science Laboratory, Fargo, ND 58102, USA
}

\section{A R T I C L E I N F O}

\section{Article history:}

Received 8 March 2012

Accepted 1 August 2012

Available online 24 August 2012

\section{Keywords:}

Stagonospora nodorum

Species complex

Coalescent

Evolution

Hybridization

\begin{abstract}
A B S T R A C T
The origin of the fungal wheat pathogen Phaeosphaeria nodorum remains unclear despite earlier intensive global population genetic and phylogeographical studies. We sequenced $1683 \mathrm{bp}$ distributed across three loci in 355 globally distributed Phaeosphaeria isolates, including 74 collected in Iran near the center of origin of wheat. We identified nine phylogenetically distinct clades, including two previously unknown species tentatively named P1 and P2 collected in Iran. Coalescent analysis indicates that P1 and P2 are sister species of $P$. nodorum and the other Phaeosphaeria species identified in our analysis. Two species, $P$. nodorum and $P$. avenaria f. sp. tritici 1 (Pat1), comprised $\sim 85 \%$ of the sampled isolates, making them the dominant wheat-infecting pathogens within the species complex. We designed a PCR-RFLP assay to distinguish $P$. nodorum from Pat1. Approximately 4\% of $P$. nodorum and Pat1 isolates showed evidence of hybridization. Measures of private allelic richness at SSR and sequence loci suggest that the center of origin of $P$. nodorum coincides with its host in the Fertile Crescent. We hypothesize that the origin of this species complex is also in the Fertile Crescent, with four species out of nine found exclusively in the Iranian collections.
\end{abstract}

(c) 2012 Elsevier Inc. All rights reserved.

\section{Introduction}

It is hypothesized that domestication of plants was accompanied by the domestication and specialization of their corresponding fungal pathogens in a pathogen emergence process known as host-tracking (Stukenbrock and McDonald, 2008). Signatures of host-tracking include elevated levels of genetic diversity and the presence of closely related ancestral pathogen species on undomesticated hosts at the domesticated host's center of origin. Specialization on the tracked host is believed to come at the cost of reduced ability to successfully colonize a broader range of plant species (Barrett et al., 2009). This specialization may lead to the emergence of new host-specialized "domesticated" pathogen species from the ancestral "wild" source populations. Two compelling examples of this process have been identified in cereal agro-ecosystems. Stukenbrock et al. (2007) found evidence to support host tracking in Zymoseptoria tritici (formerly Mycosphaerella graminicola, Quaedvlieg et al., 2011), a fungal pathogen of wheat. In Iran, near the ancient Fertile Crescent where wheat originated (Balter,

\footnotetext{
* Corresponding author. Address: Plant Pathology Group, ETH Zentrum, LFW A27, CH-8092 Zürich, Switzerland. Fax: +4144632 1572.

E-mail address: megan.mcdonald@usys.ethz.ch (M.C. McDonald).
}

2007), Stukenbrock et al. (2007) found elevated levels of genetic diversity and two newly described grass-infecting species that were shown to be the closest living relatives of the globally distributed wheat pathogen (Stukenbrock et al., 2012). Phylogeographic studies on the rice blast pathogen Magnaporthe oryzae demonstrated a single shift of the modern pathogen onto domesticated rice (Couch et al., 2005). Both Couch et al. (2005) and Stukenbrock et al. (2011) demonstrated elevated levels of pathogenicity on the tracked host and reduced virulence on closely related hosts, indicative of host-specialization.

While host-tracking in the agro-ecosystem appears to lead to host-specialized pathogens, little is known about the ecological role of the "wild" species before their emergence as global agricultural pests. A recent model proposed by Schulz and Boyle (2005), suggests that endophytes act antagonistically towards their host to facilitate colonization. This antagonism may be balanced by an equally strong defense response from the host. Pathogens could emerge from endophytes when this balance is disrupted and the immune responses of the plant are no longer sufficient to contain the endophyte (Schulz and Boyle, 2005). Experimental endophyte studies have been limited mainly to the Clavicipitaceae family. However recent reviews of endophyte diversity using both cultivable and molecular methods suggest that endophyte diversity is grossly under-estimated (Arnold, 2007; Saunders and Kohn, 
2010). Studies of agricultural endophyte communities suggest that host genotypes can have a strong effect on the structure of the endophyte community within a plant (Saunders and Kohn, 2009). Viewed within the context of the host-tracking hypothesis, it is plausible that alteration of the host environment through domestication could result in a disruption of the "balanced antagonism" and facilitate the emergence of a pathogen from an endophyte (Schulz and Boyle, 2005).

Host specialization in plant pathogenic fungi has often been used to define species groups, but this criterion can mistakenly separate fungi that are still exchanging genes (Cai et al., 2011). The most common current concept to delimit fungal species is based on Genealogical Concordance Phylogenetic Species Recognition (GCPSR) (Taylor et al., 2000). Briefly, this concept establishes species boundaries by examining concordance between multi-gene phylogenies. This concept has proven particularly useful in identifying groups of cryptic fungal species (Giraud et al., 2008). Divergence at multiple independent loci requires the interruption or gradual reduction of gene flow between two groups or populations. In allopatry, the reduction of gene flow occurs because of a physical or external barrier prohibiting genetic exchange among individuals (i.e. allopatric hosts or barriers to dispersal) (Giraud et al., 2008). In sympatry, the probability of mating should depend only on the genotype of the individuals (Kondrashov, 1986). Under this definition two species specializing on different grass hosts in the same area would be in sympatry. Specialization on one or the other host, a product of the host genotype, would reduce the chances of mating, and therefore result in sympatric speciation (Giraud et al., 2008).

Phaeosphaeria nodorum (E. Müller) (anamorph: Stagonospora nodorum (Berk.) Castellani and E.G. Germano) is a globally distributed wheat pathogen that causes significant damage in Australia and parts of North America (Solomon et al., 2006). Previous population genetic analyses, using both RFLP and micro-satellite markers in nearly 1000 global isolates, concluded that $P$. nodorum populations exhibit high levels of gene flow and high effective population sizes in Europe, North America and China (Keller et al., 1997; McDonald et al., 1999; Stukenbrock et al., 2006). Attempts to identify the center of origin of $P$. nodorum based on these populations were inconclusive, which was attributed to a lack of population samples from the Fertile Crescent (Stukenbrock et al., 2006). A complex of Phaeosphaeria cereal pathogens has appeared sporadically in the taxonomic literature since the 1950s. These morphology-based studies classified $P$. nodorum with different fungal relatives and resulted in several name changes; earlier names included Septoria nodorum and Leptosphaeria nodorum. Reviews by Cunfer and Ueng (1999) and Solomon et al. (2006) provide a more complete history of $P$. nodorum naming conventions. More recent phylogenetic studies placed $P$. nodorum within the order Pleosporales, sub-clade Phaeosphaeriaceae (Zhang et al., 2009).

Three main Phaeosphaeria-like species infecting cereals were identified in the 1950s based on spore morphology, spore production, formation of sexual structures and host specialization (Shaw, 1957a,b). Isolates that were most pathogenic on wheat and showed heterothallic mating type behavior formed the group now called $P$. nodorum. Isolates collected from oats or other hosts were initially named Leptosphaeria avenaria, with the species name reflecting the host preference. These isolates also exhibited heterothallic mating behavior (Shaw, 1957b). Subsequent molecular studies confirmed that this group also fell into the Phaeosphaeriaceae clade and it was renamed Phaeosphaeria avenaria (anamorph: Stagonospora avenae). A third group of isolates was non-pathogenic on oats, weakly pathogenic on wheat and other cereals and homothallic. These isolates were morphologically similar to $P$. avenaria but pathogenic on wheat and were therefore named Phaeosphaeria avenaria f. sp. tritici (Pat) (Shaw, 1957a; Ueng et al., 1995).
Field observations of $P$. nodorum-like symptoms on barley and other Hordeum spp. led to studies that divided $P$. nodorum into wheat or barley-infecting biotypes (Martin and Cooke, 1979). These studies confirmed field observations of stable host specialized biotypes (Osbourn et al., 1986). Restriction fragment length polymorphisms (RFLPs) (Ueng and Chen, 1994) and ITS sequences (Ueng et al., 1998) confirmed genetic differences between the two biotypes and led to the proposal to split Pat into three groups, Pat1, Pat2 and Pat3. Since 1998, the species complex was analyzed using six additional single gene phylogenies including mating-type loci (Bennett et al., 2003; Ueng et al., 2003), $\beta$-tubulin (tubA) (Malkus et al., 2005), $\beta$-glucosidase (bgl1) (Reszka et al., 2005), RNA polymerase II (Arkadiusz et al., 2006) and histidine synthase (his) (Wang et al., 2007). Until now, the phylogenetic relationships among these Phaeosphaeria spp. were assessed using single loci and a small number of isolates collected from different hosts. Results have not been consistent across all studies.

In this study we included over 300 Phaeosphaeria isolates collected from farmers' fields on five continents over 25 years in addition to over 50 isolates collected from wild grasses on different continents. While many of these isolates were used previously in population genetic studies of $P$. nodorum, we included several new collections from Iran, located near wheat's center of origin. We used a three-gene phylogeny to determine the relationships among 355 isolates within the Phaeosphaeria spp. complex, using both traditional phylogenetic and newer coalescent methods. In addition, sequences of mating type loci were analyzed for many isolates in each species. Finally we assessed allelic richness and other measures of genetic diversity within P. nodorum collections from Iran to test the hypothesis that this pathogen originated in the Fertile Crescent.

\section{Materials and methods}

\subsection{Fungal collections and DNA extraction}

Isolates used in this study are described in Table 1. Single oozing cirri from lesions were isolated with a flame-sterilized needle. Isolates were grown on Petri dishes containing Yeast Sucrose Agar (YSA, $10 \mathrm{~g} / \mathrm{L}$ Yeast Extract, $10 \mathrm{~g} / \mathrm{L}$ sucrose, $1.2 \%$ agar) amended with $50 \mu \mathrm{g}$ of kanamycin. Single colonies were transferred to $50 \mathrm{~mL}$ Yeast Sucrose Broth (YSB, $10 \mathrm{~g} / \mathrm{L}$ Yeast Extract, $10 \mathrm{~g} / \mathrm{L}$ sucrose) and grown on a rotary shaker for 3 days at $120 \mathrm{rpm}$ at $18{ }^{\circ} \mathrm{C}$. Fungal biomass was lyophilized, ground into a powder and total DNA was extracted using the DNeasy Plant Mini DNA extraction kit (Qiagen $\mathrm{GmbH}$, Hilden, Germany) following the manufacturer's instructions. Extracted DNA was diluted 1:500 with sterile water for PCR amplification.

\subsection{PCR amplification, restriction enzyme digestion, sequencing and alignment}

PCR amplification was performed in $20 \mu \mathrm{L}$ reactions containing $0.05 \mu \mathrm{M}$ of each primer (Microsynth, Balgach Switzerland), $1 \times$ Dream Taq Buffer (MBI Fermentas), $0.4 \mu$ M dNTPs (MBI Fermentas) and 0.5 units of Dream Taq DNA polymerase (MBI Fermentas). The PCR cycle parameters were: 2 min initial denaturation at $96{ }^{\circ} \mathrm{C}$ followed by 35 cycles of $96^{\circ} \mathrm{C}$ for $30 \mathrm{~s}$, anneal for $45 \mathrm{~s}$, and extend at $72{ }^{\circ} \mathrm{C}$ for $1 \mathrm{~min}$. A final $7 \mathrm{~min}$ extension was made at $72{ }^{\circ} \mathrm{C}$. A portion of the $\beta$-tubulin gene (annotated as SNOG06791.2 in the $P$. nodorum genome sequence available at http://genome.jgi-psf.org/ Stano2/Stano2.home.html), the internal transcribed spacer (ITS) of the ribosomal gene cluster, and a portion of a $\beta$-xylosidase gene (SNOG06123.2) were amplified and sequenced in all isolates (Hane et al., 2007). The mating type idiomorphs MAT1-1 (SNOG00375.2) 
Table 1

List of regional collections, sample sizes and host source for all isolates.

\begin{tabular}{|c|c|c|c|c|c|}
\hline Populations & Year & Collector & Location & $N$ & Host source \\
\hline \multicolumn{6}{|l|}{ Asia } \\
\hline \multirow[t]{3}{*}{ Iran } & 2005 & R. Sommerhalder & Golestan Province & 42 & Wheat (ears) \\
\hline & 2010 & M. Razavi & Golestan Province & $15^{d}$ & Wheat (ears) \\
\hline & 2011 & M. Razavi & Golestan Province & $17^{\mathrm{d}}$ & Elymus tauri; Agropyron tauri \\
\hline Azerbaijan & 2005 & R. Sommerhalder & & $12^{\mathrm{d}}$ & Wheat \\
\hline Kazakhstan & 2003-2004 & H. Maraite, E. Duveiller & & 23 & Wheat \\
\hline Tajikistan & 2004 & H. Maraite, E. Duveiller & & 5 & Wheat \\
\hline Kyrgyzstan & 2003 & H. Maraite, E. Duveiller & & 1 & Wheat \\
\hline Russia & 2003 & H. Maraite, E. Duveiller & & 4 & Wheat/durum wheat \\
\hline China & 2001 & R. Wu & Fujian Province & 8 & Wheat \\
\hline \multicolumn{6}{|l|}{ Europe } \\
\hline England & 2005 & T.W. Hollins & Cambridge & $1^{\mathrm{d}}$ & \\
\hline Denmark & 2005 & E. Stukenbrock & Jylland & $37^{d}$ & Triticale/wheat \\
\hline Sweden & 2005 & E. Blixt & & 15 & Wheat \\
\hline Switzerland & 1994 & S. Keller & Zurich & 7 & Wheat \\
\hline \multicolumn{6}{|l|}{ North America } \\
\hline \multirow[t]{3}{*}{ Canada } & 1991 & R. Clear & Alberta & $18^{\mathrm{d}}$ & Wheat (seed) \\
\hline & 1991 & R. Clear & Manitoba & $7^{d}$ & Wheat (seed) \\
\hline & 1991 & R. Clear & Saskatchewan & $23^{d}$ & Wheat (seed) \\
\hline \multirow[t]{11}{*}{ United States } & 1986-1992 & J. Krupinsky & North Dakota $(C W G)^{b}$ & $33^{d}$ & A. cristatum \\
\hline & 1993 & M. Schmidt & Oregon & 10 & Wheat \\
\hline & 1991 & G. Milus, M. Gray & Arkansas & 8 & Wheat (seed) \\
\hline & 1979 & J. Krupinsky & North Dakota $(A V R)^{c}$ & $2^{\mathrm{d}}$ & Agropyron sp., A. intermedium \\
\hline & 1982 & J. Krupinsky & North Dakota (AVR) ${ }^{\mathrm{c}}$ & $4^{\mathrm{d}}$ & Altai wild rye, smoothe brome \\
\hline & 1984 & J. Krupinsky & North Dakota (AVR) ${ }^{\mathrm{c}}$ & $3^{d}$ & Smoothe brome \\
\hline & 1985 & J. Krupinsky & North Dakota (VIR) ${ }^{\mathrm{c}}$ & $1^{\mathrm{d}}$ & Wild rye \\
\hline & 1993 & L. Francl & North Dakota & 3 & Wheat \\
\hline & 1998 & J. Krupinsky & North Dakota $(\mathrm{VIR})^{\mathrm{c}}$ & $8^{\mathrm{d}}$ & Barley \\
\hline & 2003 & P. Lips & OH03 Sn1501 (VIR) ${ }^{\mathrm{c}}$ & $1^{\mathrm{d}}$ & Wheat \\
\hline & 2006 & T. Friesen & North Dakota & $12^{\mathrm{d}}$ & Wheat \\
\hline \multicolumn{6}{|l|}{ South Africa } \\
\hline & 2007 & Z. Pretorius & Western Cape & $32^{\mathrm{d}}$ & Wheat \\
\hline $\mathrm{SN} 15^{\mathrm{a}}$ & & Aus. Dept. Agriculture & Australia & 1 & Wheat \\
\hline Sn79-1087 & 1979 & J. Krupinsky & North Dakota (AVR) ${ }^{\mathrm{c}}$ & 1 & Grass \\
\hline $\mathrm{Sn} 4^{\mathrm{a}}$ & & T. Friesen & North Dakota $(\mathrm{VIR})^{\mathrm{c}}$ & 1 & Wheat \\
\hline P. avenaria & 2009 & K. Clarke & Australia (Mt. Barker) & 1 & Oat \\
\hline P. avenaria & 2005 & Cent. Bur. Schimmelcul. & Baarn, Netherlands & 1 & \\
\hline Total & 1979-2011 & & & 355 & \\
\hline
\end{tabular}

a Isolates for which genome sequence is available.

b Isolates collected from North Dakota on crested wheatgrass (CWG).

c Populations which have known phenotypes avirulent (AVR) or virulent (VIR).

d Collections used for the first time in this publication.

and MAT1-2 were sequenced for a subset of isolates. The conserved mating type (MAT) primers for P. nodorum (Bennett et al., 2003) were used to amplify and sequence the MAT loci from all Phaeosphaeria spp. Sample size permitting, we assessed the ratio of MAT1-1 to MAT1-2 alleles. Primer sequences and annealing temperatures specific for each pair are listed in Appendix A.1.

Sequencing reactions were conducted in $10 \mu \mathrm{L}$ volume using the BigDye ${ }^{\circledR}$ Terminator v3.1 Sequencing Standard Kit (Life Technologies, Applied Biosystems) with both the forward and reverse primers. The cycling parameters were $96{ }^{\circ} \mathrm{C}$ for $2 \mathrm{~min}$ followed by 55 or 99 cycles of $96^{\circ} \mathrm{C}$ for $10 \mathrm{~s}, 50^{\circ} \mathrm{C}$ for $5 \mathrm{~s}$ and $60^{\circ} \mathrm{C}$ for 4 min. PCR products were cleaned with the illustra ${ }^{\mathrm{TM}}$ Sephadex ${ }^{\mathrm{TM}}$ G-50 fine DNA Grade column (GE Healthcare) according to the manufacturer's recommendations and sequenced with a 3730xl Genetic Analyzer (Life Technologies, Applied Biosystems). Alignment of forward and reverse sequences was performed in SeqScape software V2.5 (Life Technologies, Applied Biosystems). Quality screening and ambiguous base calls were edited by hand using SeqScape. Final alignments were exported and re-aligned using ClustalW, implemented online using the Max Planck Institute of Bioinformatics Toolkit (http://toolkit.tuebingen.mpg.de). Sequences of each isolate were concatenated using the utility function implemented in SNAP Workbench (Price and Carbone, 2005). Each locus was tested for neutrality using the standard measure- ments implemented in DnaSP v5 (Rozas and Rozas, 1995; Librado and Rozas, 2009).

\subsection{Phylogenetic relationships and coalescence dating}

Bayesian and maximum-likelihood methods were used to determine the phylogenetic relationship among isolates. Orthologous sequences from Pyrenophora tritici-repentis were used to root the phylogenies. The program jModelTest v0.1 (Guindon and Gascuel, 2003; Posada, 2008) was used to select the most appropriate nucleotide substitution model for each locus. Top models were chosen based on the corrected Akaike Information Criterion (AICc). For $\beta$-tubulin the top AICc model was $\operatorname{TrN}+\mathrm{I}+\mathrm{G}$. For ITS the top model was GTR $+G$ and for $\beta$-xylosidase the top model was TIM2 + G. The top model of the concatenated dataset was TI$\mathrm{M} 2+\mathrm{I}+\mathrm{G}$. The most commonly implemented model which was also ranked by AICc within the top 12 nucleotide models for all three loci was GTR + G.

The program RaxML v7.2.1 (Stamatakis, 2006; Stamatakis et al., 2008) was used to calculate the tree with the highest likelihood and MrBayes v4.1.2 (Ronquist and Huelsenbeck, 2003; Altekar et al., 2004) was used for Bayesian posterior sampling. To reduce computation time, the data set was condensed into distinct sequence haplotypes, excluding indels and infinite site violations, 
using the program MAP implemented in SNAP workbench (Aylor et al., 2006). The MAT idiomorphs were analyzed separately using RaxML v7.2.1.

For RaxML runs we used the "-f a" algorithm which performs a rapid bootstrap analysis while simultaneously searching for the best maximum likelihood tree. Bootstrap scores were plotted onto the highest scoring maximum likelihood tree with 10,000 bootstrap replicates. The author recommended nucleotide model GTR-CAT was selected over the GTR + G model due to computational advantages within RAxML (Stamatakis, 2006). For Bayesian analysis the nucleotide substitution model GTR was used with a gamma distribution to account for variation in mutation rates at different sites. The default four gamma categories were used. The chain length was set to 15 million generations and posterior samples were recorded every 1000 generations. The first $25 \%$ of trees (3750) were discarded as burn-in. To ensure convergence, replicate independent runs were conducted to ensure that both runs reached similar Ln-likelihood scores.

Coalescent and species tree construction were conducted using the Bayesian Markov Chain Monte Carlo (MCMC) methods implemented in the program BEAST v1.6.1 (Drummond and Rambaut, 2007). ${ }^{*}$ BEAST was used to calculate the species tree (Heled and Drummond, 2010). *BEAST allows uncoupling of the gene trees to estimate the species tree, thereby taking into account incongruence among the gene trees used to construct the Bayesian estimated species tree. The data set was partitioned by locus in the nexus input file so that parameters for each gene could be estimated separately. The entire nucleotide dataset was used for this analysis. Simulations were conducted with all loci under the HKY or GTR model. Due to computational time limits, rate variation was left out of the nucleotide model. All 355 Phaeosphaeria isolates were assigned to species groups a priori based on the results from the maximum-likelihood and Bayesian phylogenetic analyses. Runs were conducted using a strict molecular clock under the Yule's speciation model specified in BEAUti. The XML file, which contains the exact parameters used for this analysis, is available for public download at Dryad (http://www.datadryad.org). Posterior sampled trees were visualized after burn-in of $25 \%$ of the sampled trees. The posterior sampling was visualized in the form of consensus species trees using DensiTree (Bouckaert, 2010).

Relative time of divergence was also estimated in *BEAST. For estimation of divergence times for the individual species, all individuals were assigned a priori to groups based on the results from the previous MrBayes and RaxML analyses. Additional taxonomic groups were added to estimate time to the most recent common ancestor (TMRCA) of groups of species at nodes deeper in the tree (i.e. TMRCA of the ancestor of $P$. nodorum and the other Phaeosphaeria spp.). Estimation of all parameters was conducted under two different clock models; strict and relaxed exponential. The complementary program BEAUti (Drummond and Rambaut, 2007) was used to prepare the XML file needed for input into *BEAST. Runs were assessed for convergence using the Estimated Sample Size (ESS) values for each parameter calculated in the program Tracer v1.5 (Rambaut and Drummond, http://beast.bio.ed.ac.uk/Tracer). As suggested by the authors all runs were conducted until ESS values exceeded 100 for all estimated parameters. Means and 95\% highest posterior density (HPD) intervals for all runs and combined runs were also calculated and plotted using Tracer.

\subsection{Allelic diversity in P. nodorum and Pat1}

Stukenbrock et al. (2006) previously described the allelic diversity and migration patterns among global collections of $P$. nodorum. This dataset was restricted to the nine largest single field collections made in China, Australia, Texas, North Dakota, Oregon, New York, South Africa and Switzerland. We added our largest Iranian field population, collected in 2005 , to this dataset to compare allelic richness at eight micro-satellite (SSR) loci. In a second analysis we included another Iranian field population sampled from the same region in 2010 in order to increase the sample size from Iran. Amplification of SSR loci was performed using labeled primers as described previously (Stukenbrock et al., 2005). Amplicons were separated in a 3730xl Genetic Analyzer (Life Technologies, Applied Biosystems). The software Genemapper (Life Technologies, Applied Biosystems) was used for genotyping. The program ADZE v1.0 was used to visualize SSR average allelic richness and private allelic richness across all eight loci (Szpiech et al., 2008). The program plots both values as a function of sample size $(\mathrm{g})$, which allows comparison across populations with unequal sample sizes.

For $P$. nodorum and Pat 1 the number of sequence alleles (haplotypes) per locus was summarized in R using the pegas library (Paradis, 2010). Rarefaction analysis of haplotype diversity was performed using the methods described by Simberloff (1972) and a rarefied sample size of 15 . The program implementing these methods is available online at http://www.biology.ualberta.ca/jbrzusto/ rarefact.php. Significance of differences in rarefied allelic richness in each field population was determined using Bonferroni-corrected $T$-tests. To determine if there were significant differences in the proportion of observed private alleles between field populations, Fisher's exact tests were used (Fisher, 1925). Fisher's exact tests were performed for $r \times c$ contingency tables as implemented in the base statistical package in $\mathrm{R}$ (http://cran.r-project.org/).

The minimum number of recombination events ( $\mathrm{Rm})$ and number of pairs of sites with four gametes was also assessed using DnaSP v5 (Librado and Rozas, 2009). The program TCS v1.2 was used to visualize the multi-locus haplotype network of the Pat1 species (Clement et al., 2000). This program generates a haplotype network within which possible recombination events are allowed in the network construction. Pie charts showing the frequency of multi-locus haplotypes in each population were generated using the pegas package in $\mathrm{R}$ (Paradis, 2010).

We developed a PCR-restriction fragment length polymorphism (PCR-RFLP) assay using fixed species polymorphisms to distinguish between $P$. nodorum and Pat1. The 962 bp amplicon from $\beta$-xylosidase (SNOG06123.2) was used as the template DNA. NEB Cutter v2.0 was used to identify species-specific restriction enzyme recognition sites. PCR amplicons were digested with 2 units of the restriction enzyme Scal (NE Biolabs) at $37{ }^{\circ} \mathrm{C}$ for $90 \mathrm{~min}$, followed by $15 \mathrm{~min}$ of heat inactivation at $65^{\circ} \mathrm{C}$. Digested products were separated in $1.8 \%$ agarose gels and visualized under UV light using ethidium bromide staining.

\subsection{Southern blotting and hybridization}

Genomic DNA was blotted onto nylon membranes using a BioDot microfiltration apparatus (BIO-RAD) following the instructions in the user manual. Radioactive probes were synthesized using purified PCR product (purification same as above). Probe labeling with ${ }^{32} \mathrm{P}$ was performed with $25-50 \mathrm{ng} / \mu \mathrm{L}$ of template DNA using the NEBlot Kit (NE Biolabs) following the manufacturer's recommendations. Unincorporated nucleotides were filtered out using illustra NICK ${ }^{\mathrm{TM}}$ columns (GE Healthcare). DNA hybridization, membrane washing and image acquisition were performed as described previously (McDonald and Martinez, 1990).

\section{Results}

\subsection{Phylogenetic analyses}

The complete ITS region (502 bp) and partial nucleotide sequences of the $\beta$-tubulin (490 bp) and $\beta$-xylosidase genes 
(689 bp) were concatenated and used for phylogenetic analysis of 355 Phaeosphaeria isolates (Fig. 1A). This multi-locus dataset used the closest known pathogenic relatives of $P$. nodorum, Leptosphaeria maculans and Pyrenophora tritici-repentis, as outgroups. Based on the genes used in this study, $P$. tritici-repentis is more closely related to the Phaeosphaeria species complex than L. maculans. Therefore, all further analyses requiring an outgroup were performed with $P$. tritici-repentis. All three loci displayed neutral evolution. The dataset collapsed into 149 multi-locus haplotypes distributed among nine distinct phylogenetic groups (Fig. 1A). The complete dataset is available for download through GenBank: accession numbers JQ757169-JQ758513.

$P$. nodorum formed the largest clade, found on wheat leaves, ears and seeds, barley, triticale, crested wheatgrass (Agropyron cristatum) and other wild grasses. Pat1 was the second largest clade, but found only on wheat leaves, ears and seeds. Six Pat3 isolates were isolated from triticale and wheat leaves in Denmark. In addition to these described species, several new clades were discovered. To be consistent with earlier publications the new clades were named using the $P$. avenaria f. sp. tritici (Pat) notation adopted by Malkus et al. (2005). All Pat4 isolates were isolated from Elymus tauri in Iran. Pat6 isolates were found on both E. tauri and Agropyron tauri in Iran. Pat5 was isolated from Elymus angustus and Bromus inermis in North Dakota between 1982 and 1984 (Krupinsky, 1982). These Pat5 isolates have been characterized as non-pathogenic on wheat ( $\mathrm{T}$. Friesen, unpublished data).

We found 29 P. nodorum isolates, 19 Pat1 isolates and two undescribed species, provisionally named P1 (Phaeosphaeria 1, seven isolates) and P2 (Phaeosphaeria 2, two isolates) in Iranian wheat fields. Unrestricted BLAST searches in GenBank using the P1 and P2 sequences found significant similarity to both $P$. nodorum and $P$. avenaria for the $\beta$-tubulin and $\beta$-xylosidase loci. Unrestricted searches with the ITS region of P1 found $>98 \%$ sequence identity to several fungi described as Leptosphaeria sp., Pleosporales sp. or unknown fungal species. The GenBank accession numbers, location of sampling, sampling method, and type of study for hits with $100 \%$ query coverage and $>98 \%$ identity are as follows, GB accessions: AB693774.1 (unknown), GU985210.1 (China, cultured, endophyte), GU985209.1 (China, cultured, endophyte), GU985203.1 (China, cultured, endophyte), HM537061.1 (China, unknown, endophyte), GU078648.1 (China, uncultured, rice paddy soil), FJ537121.1 (unknown), AJ608969.1 (Bulgaria, cultured, plastic), FN5481557.1 (Germany, cultured, endophyte), EF505560.1 (Ohio, uncultured, endophyte). Most of these studies described fungal leaf endophytes on a wide variety of hosts. The ITS BLAST search for P2 found 99\% identity to two uncultured fungal clones found in air samples in Germany (GB accessions: GQ999266.1, FJ820759.1). Other matches with lower identity (96\%) included the soil fungal community of grasslands in New Mexico (GB: EU479755.1, EU479754.1), a fungal community of ants in Texas (GB: HQ608028.1) and endophytes of cupressaceous trees (GB: EF420004.1). The ITS sequence similarity of $\mathrm{P} 1$ and $\mathrm{P} 2$ to P. nodorum averaged $89 \%$ for both groups. This is moderately higher than the ITS similarity between $P$. nodorum and $P$. tritici-repentis (85\%). A complete list of the top 250 BLAST hits for both P1 and P2 is available in Appendices C and D.

Both tree construction methods separated all nine phylogenetic groups into distinct clades with both bootstrap and posterior probability support estimates (Fig. 1A). Maximum-likelihood trees constructed using each locus separately gave similar results (Appendix B.1, 2 and 3). All clade-defining branches were highly supported using both Bayesian and maximum-likelihood methods, but some intermediate branches had low bootstrap values. The number of isolates within each clade is given in Table 2 . Fixed nucleotide differences between species were used to design a PCR-RFLP assay to distinguish P. nodorum from Pat1 (Fig. 2). This method was tested on 96 P. nodorum isolates from eight different global populations and 68 Pat 1 isolates from 4 different global populations. The method identified the species correctly for every isolate tested. The number of fixed differences and the average number of nucleotide substitutions between each species pair is summarized in Appendix A.2.

The mating-type primers successfully amplified the corresponding loci from P. avenaria and all Pat clades, but did not amplify the more distant P1 and P2 clades. Southern hybridization of P1 and P2 DNA with P. nodorum MAT1-1 and MAT1-2 probes was also negative. A summary of mating type assignments for the entire dataset is presented in Table 2. For the MAT1-1 idiomorph, $80 P$. nodorum isolates were sequenced and collapsed into seven nucleotide haplotypes ( 5 with synonymous mutations, 2 with non-synonymous mutations). For the MAT1-2 idiomorph, five haplotypes (4 synonymous, 1 non-synonymous) were found among $117 \mathrm{P}$. nodorum isolates. A summary of the non-synonymous and synonymous substitutions found between mating type idiomorphs among all species is given in Appendix A.3.

All Pat1 isolates carried only the MAT1-1 allele. Absence of the MAT1-2 locus was confirmed with Southern hybridization. MAT11 sequences in 38 Pat1 isolates collapsed into a single haplotype. Both MAT1-1 and MAT1-2 alleles were found among the Pat3 and Pat5 isolates. P. avenaria, Pat4, and Pat6 isolates were all MAT1-2, but small sample sizes may explain the lack of MAT1-1. Figs. 1B and $C$ show the maximum likelihood trees with 1000 bootstrap replicates for MAT1-1 and MAT1-2, respectively.

\subsection{Evidence for genetic exchange between P. nodorum and Pat1}

We observed three multi-locus haplotypes (six individuals) that possessed a $\beta$-tubulin haplotype identical to a Pat1 haplotype, with all other sequences classifying these isolates as $P$. nodorum. These six isolates were sampled at the same time from crested wheatgrass (A. cristatum) plants growing in close proximity to each other. Two of the three multi-locus haplotypes contained isolates with opposite $P$. nodorum mating-types, indicating that they were not the same clone. The mating-type of the third multi-locus haplotype could not be determined.

Five multi-locus haplotypes (eight isolates) carried a $P$. nodorum $\beta$-tubulin allele but Pat1 alleles for the other genes. Three of these haplotypes had $\beta$-tubulin sequences that were identical to three different $P$. nodorum haplotypes. Two of the $\beta$-tubulin haplotypes were unique and appear to have arisen through intragenic recombination of existing P. nodorum point mutations (Fig. 3). These isolates originated from a seed collection made in Canada that encompassed at least several hundred square kilometers. One of the eight isolates had a $P$. nodorum MAT1-1 allele and a second isolate carried a $P$. nodorum MAT1-2 allele.

A comparison of the minimum number of recombination events within each locus for $P$. nodorum, Pat1 and the hybrid isolates is shown in Table 3. In isolates that were strictly classified as Pat1, there was no evidence for intra-locus recombination for any locus. In $P$. nodorum there was evidence for several recombination events within loci. In the hybrid $P$. nodorum isolates carrying a Pat1 $\beta$-tubulin sequence there was no evidence of recombination. The Pat1 isolates carrying a $P$. nodorum $\beta$-tubulin, however, showed evidence of intragenic recombination at the $\beta$-tubulin locus. At the multi-locus level there was evidence for at least ten recombination events in $P$. nodorum. Pat1 isolates showed a minimum of one recombination event between loci. Pat1 hybrid isolates showed some evidence of recombination at the multi-locus level.

\subsection{Estimates of species divergence using *BEAST}

A posterior sample of species trees, constructed using the independently modeled gene trees, was generated using *BEAST. A sample containing $\sim 96 \%$ of all posterior trees collapsed into nine 
A Multi-locus phylogeny

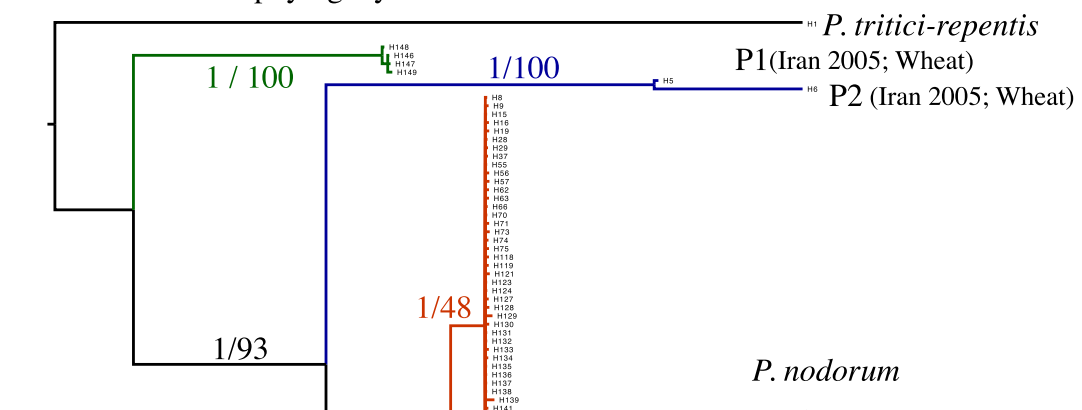

"'P. tritici-repentis

$0 . \overline{\mathrm{sub} / \mathrm{site}}$

B Mat1-1

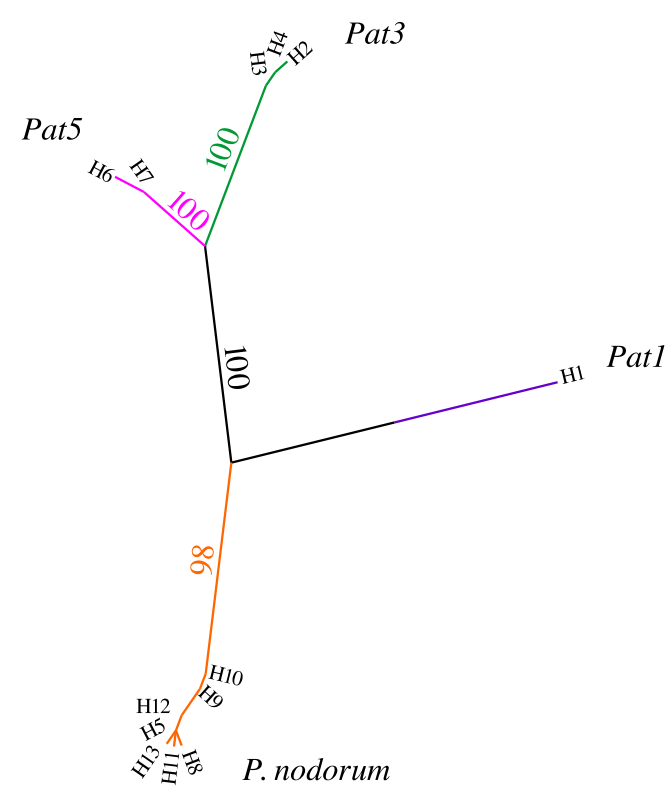

0.02
(Iran 2005, 2010; Wheat

Central Asia 2003, 2004; Wheat

China 2001, Wheat

Europe 1994, 2005; Triticale, Wheat

United States 1979-2006; Grass sp.,

Wheat, Barley, Wild Rye

South Africa 1995, 2007; Wheat)

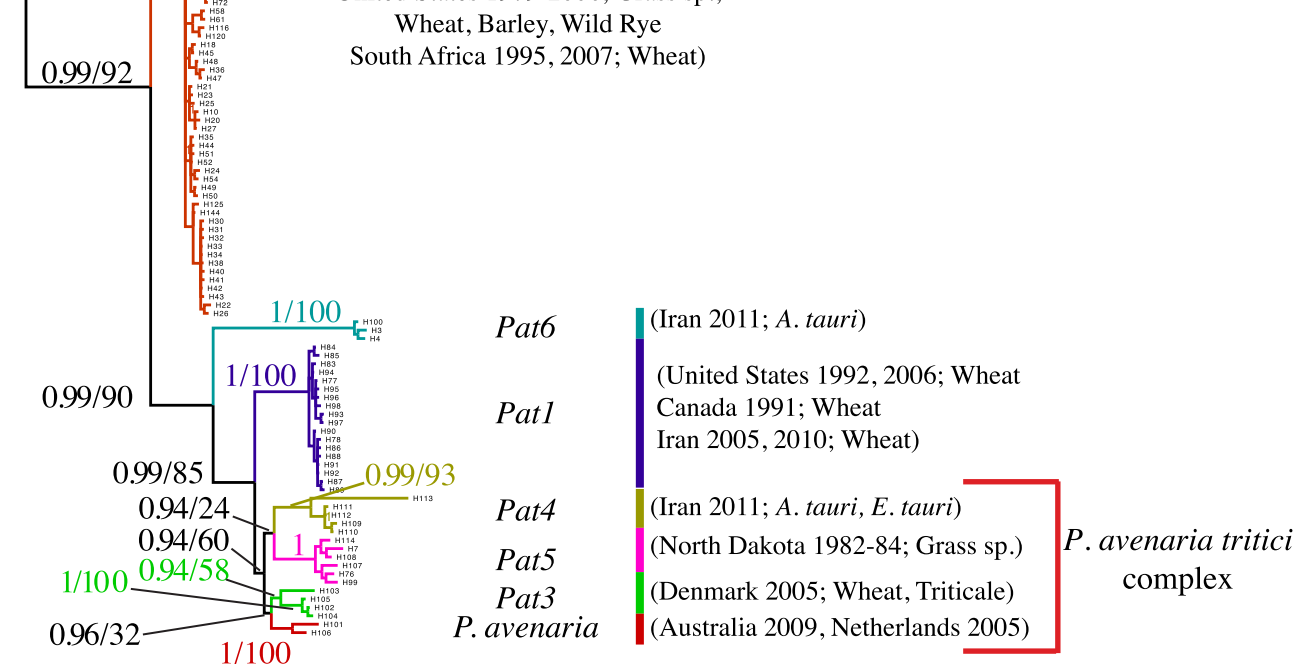

C Mat1-2

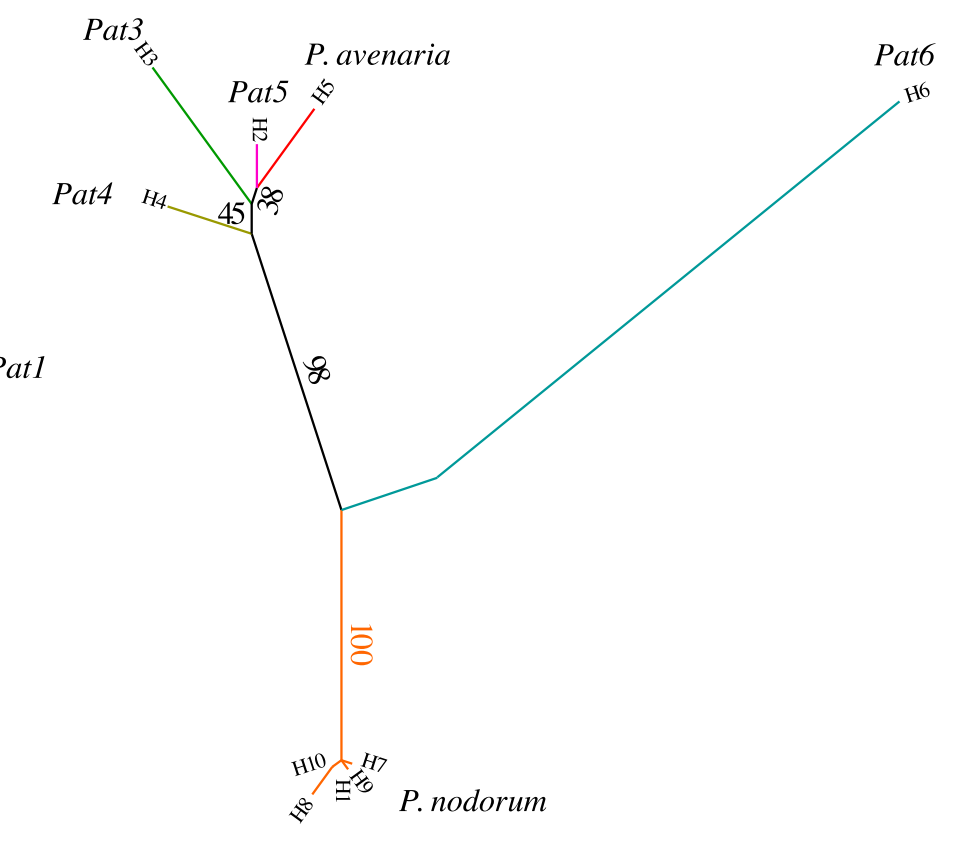

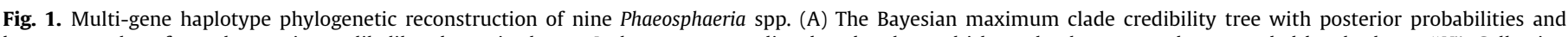

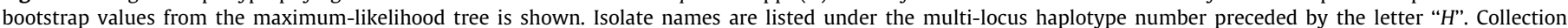

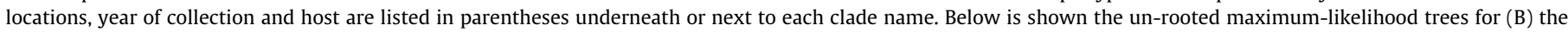

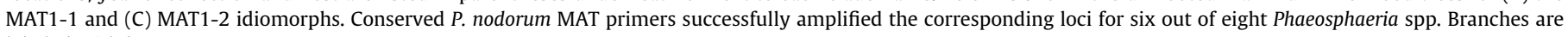
labeled with bootstrap support. 
Table 2

Number of Phaeosphaeria isolates and mating type assignment by region and species.

\begin{tabular}{|c|c|c|c|c|c|}
\hline Region & Species & $N$ isolates & $N$ MAT1-1 & $N$ MAT1-2 & $N \mathrm{ND}^{\mathrm{a}}$ \\
\hline \multicolumn{6}{|l|}{ Asia } \\
\hline \multirow[t]{6}{*}{ Iran } & P. nodorum ${ }^{\mathrm{b}}$ & 29 & 10 & 19 & \\
\hline & Pat $^{\text {b }}$ & 19 & 19 & & \\
\hline & Pat $4^{\mathrm{b}}$ & 10 & & 10 & \\
\hline & Pat6 $^{\mathrm{b}}$ & 7 & & 4 & 3 \\
\hline & $\mathrm{P} 1^{\mathrm{b}}$ & 7 & & & 7 \\
\hline & $\mathrm{P} 2^{\mathrm{b}}$ & 2 & & & 2 \\
\hline \multirow[t]{2}{*}{ Central Asia } & P. nodorum & 40 & 18 & 20 & 2 \\
\hline & Pat1 & 5 & & & 5 \\
\hline China & P. nodorum & 8 & 2 & 5 & 1 \\
\hline \multicolumn{6}{|l|}{ Europe } \\
\hline England & P. nodorum & 1 & & 1 & \\
\hline Netherlands & P. avenaria ${ }^{\mathrm{b}}$ & 1 & & 1 & \\
\hline \multirow[t]{2}{*}{ Denmark } & P. nodorum & 31 & 14 & 16 & 1 \\
\hline & Pat $3^{\mathrm{b}}$ & 6 & 3 & 2 & 1 \\
\hline Sweden & P. nodorum & 15 & 2 & 12 & 1 \\
\hline Switzerland & P. nodorum & 7 & 5 & 2 & \\
\hline \multicolumn{6}{|l|}{ North America } \\
\hline Oregon & P. nodorum & 10 & 3 & 7 & \\
\hline \multirow[t]{3}{*}{ North Dakota } & P. nodorum & 4 & 1 & 3 & \\
\hline & Pat1 & 8 & 8 & & \\
\hline & Pat1 hybrid & 1 & & 1 & \\
\hline North Dakota AVR & P. nodorum & 3 & 1 & 2 & \\
\hline North Dakota AVR & Pat5 $5^{\mathrm{b}}$ & 7 & 5 & 2 & \\
\hline North Dakota VIR & P. nodorum & 11 & 3 & 8 & \\
\hline \multirow[t]{2}{*}{ North Dakota CWG } & P. nodorum & 27 & 11 & 15 & 1 \\
\hline & P. nod. hybrid & 6 & 2 & 3 & 1 \\
\hline Arkansas & P. nodorum & 8 & 4 & 4 & \\
\hline \multirow[t]{2}{*}{ Canada } & Pat1 & 41 & 41 & & \\
\hline & Pat1 hybrid & 7 & 7 & & \\
\hline South Africa & P. nodorum & 32 & 17 & 15 & \\
\hline \multicolumn{6}{|l|}{ Australia } \\
\hline & P. nodorum & 1 & 1 & & \\
\hline & P. avenaria & 1 & & & 1 \\
\hline Total & & 355 & 177 & 151 & 26 \\
\hline
\end{tabular}

${ }^{\text {a }}$ ND - not determined because amplification did not work.

b Phaeosphaeria nodorum; Phaeosphaeria avenaria; Phaeosphaeria avenaria tritici 1; Phaeosphaeria avenaria tritici 3; Phaeosphaeria avenaria tritici 4; Phaeosphaeria avenaria tritici 5; Phaeosphaeria avenaria tritici 6; Phaeosphaeria sp. 1; Phaeosphaeria sp. 2.

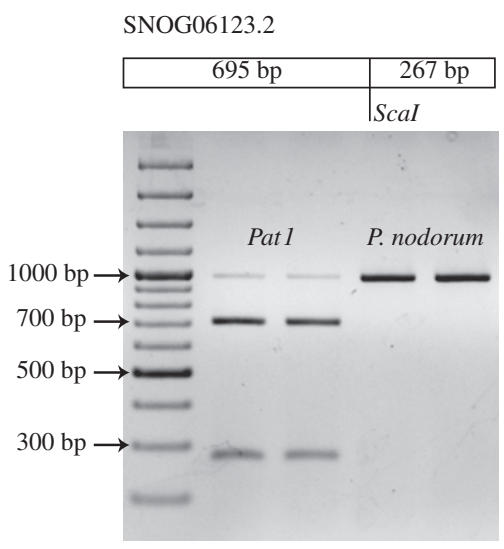

Fig. 2. PCR-RFLP assay designed to distinguish between $P$. nodorum and Pat1. The 962 base pair amplicon corresponding to SNOG_06123.2 ( $\beta$-xylosidase) is amplified in both species. Pat1 isolates possess one specific restriction site for Scal, resulting in fragments visible at $695 \mathrm{bp}$ and at $267 \mathrm{bp}$. Faint bands of incomplete digestion are present in the Pat1 samples. P. nodorum isolates lack a Scal restriction site, leaving the uncut $962 \mathrm{bp}$ amplicon.

different consensus trees, shown in Fig. 4A. All remaining consensus trees represented less than one percent of the posterior sample. Appendix B.4 shows the maximum clade credibility tree for each of the three loci individually. These gene trees are the decomposed versions of the composite species tree presented in Fig. 4A. This analysis established a clear separation between the time to most recent common ancestor (TMRCA) of P1 and P2 and the remaining Phaeosphaeria species. P1 and P2 split earlier from the other Phaeosphaeria spp., as shown by the high branching points in Fig. 4A. Crossing over of branches between P1 and P2 indicate that the analysis was not able to resolve the precise relationships among these groups. Given this lack of consistency in the species trees in the posterior sample, it is unclear whether P1 or P2 shares the most recent common ancestor (MRCA) with the Phaeosphaeria spp. clade. Estimates for the TMRCA for each individual species or group of species are shown in Fig. 4B. The TMRCA estimate for the entire Phaeosphaeria species clade is marked by a red asterisk in both Fig. 4A and B. The flattened posterior probability density peak in Fig. 4B indicates a wide confidence interval for this estimate, which is illustrated in the varying height of the final node in the consensus trees. Additional informative sequence loci will be needed to provide more resolution for the older splitting events.

Enclosed in the red box in Fig. 4A are the remaining species, termed "young Phaeosphaeria". To make the tree more legible, all isolates belonging to the $P$. avenaria (tritici) complex (marked by a red bracket in Fig. 1) were condensed into a single group. This simplification did not change the topology compared to an analysis where all groups were classified separately. The TMRCA of the young Phaeosphaeria is labeled with a black asterisk in both Fig. 4A and B. In Fig. 4B the narrowed peak for the TMRCA indicates a smaller confidence interval for this parameter. The smaller confidence interval is also seen in the illustration of the consensus 


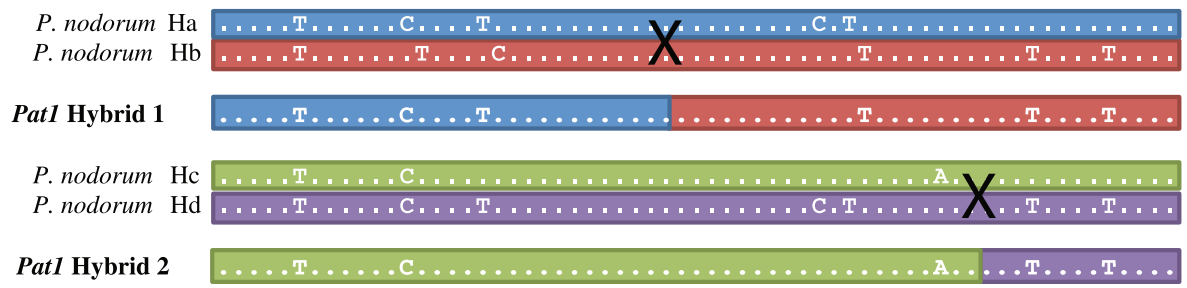

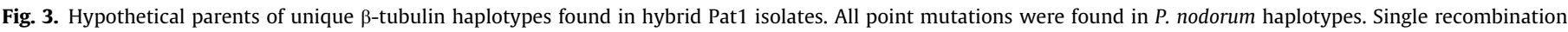
events can explain the two unique $\beta$-tubulin haplotypes found in Pat1 hybrids.

Table 3

Phaeosphaeria nodorum and Phaeosphaeria avenaria tritici 1 minimum number of intragenic recombination events by locus.

\begin{tabular}{|c|c|c|c|c|c|}
\hline \multirow[t]{2}{*}{ Locus } & & \multicolumn{4}{|c|}{ Multi-locus species classification } \\
\hline & & P. nodorum & Pat1 & P. nodorum hybrid & Pat1 hybrid \\
\hline \multirow{6}{*}{$\beta$-Tubulin } & $N$ isolates & 227 & 73 & 6 & 8 \\
\hline & $N$ haplotypes & 32 & 2 & 2 & 6 \\
\hline & $N$ sites $^{\mathrm{a}}$ & 479 & 479 & 479 & 479 \\
\hline & $N$ polymorphic ${ }^{\mathrm{b}}$ & 21 & 1 & 1 & 13 \\
\hline & Pairs 4-gamete & 70 & 0 & 0 & 15 \\
\hline & $\operatorname{Min} \operatorname{Rec}^{c}$ & 6 & 0 & 0 & 4 \\
\hline \multirow[t]{5}{*}{$\beta$-Xylosidase } & $N$ haplotypes & 15 & 8 & 4 & 2 \\
\hline & $N$ sites $^{\mathrm{a}}$ & 687 & 687 & 687 & 687 \\
\hline & $N$ polymorphic ${ }^{b}$ & 68 & 10 & 4 & 4 \\
\hline & Pairs 4-gamete & 13 & 0 & 0 & 0 \\
\hline & $\operatorname{Min} \operatorname{Rec}^{\mathrm{C}}$ & 3 & 0 & 0 & 0 \\
\hline \multirow[t]{5}{*}{ ITS region } & $N$ haplotypes & 7 & 6 & 2 & 3 \\
\hline & $N$ sites $^{\mathrm{a}}$ & 468 & 475 & 475 & 475 \\
\hline & $N$ polymorphic ${ }^{\mathrm{b}}$ & 18 & 6 & 5 & 2 \\
\hline & Pairs 4-gamete & 5 & 0 & 0 & 0 \\
\hline & $\operatorname{Min} \operatorname{Rec}^{\mathrm{C}}$ & 2 & 0 & 0 & 0 \\
\hline \multirow[t]{5}{*}{ Multi-locus } & $N$ haplotypes & 92 & 17 & 4 & 7 \\
\hline & $N$ sites $^{\mathrm{a}}$ & 1633 & 1641 & 1641 & 1641 \\
\hline & $N$ polymorphic ${ }^{\mathrm{b}}$ & 44 & 17 & 10 & 19 \\
\hline & Pairs 4-gamete & 327 & 12 & 0 & 24 \\
\hline & Min $\operatorname{Rec}^{\mathrm{C}}$ & 10 & 1 & 0 & 5 \\
\hline
\end{tabular}

\footnotetext{
a Number of nucleotide sites for within species alignment.

b Number of polymorphic nucleotide sites.

c The minimum number of recombination events.
}

trees, where there is a high amount of overlap for the height of the nodes defining the young Phaeosphaeria clade. There were several crossing branches among consensus trees, making it difficult to conclude which of the species shared a common ancestor before the ancestor marked by the black asterisk. Pat1 is estimated to be the youngest group, followed by Pat6, $P$. nodorum, and the $P$. avenaria (tritici) complex (Fig. 4B).

\subsection{Allelic diversity at the hypothesized center of origin}

Allelic richness at eight micro-satellite loci in the largest Iranian $P$. nodorum population was compared with previously analyzed single field populations (Stukenbrock et al., 2006). As sample size increased, the Iranian population showed allelic richness similar to China, Switzerland and New York. The Iranian field population, however, contained a larger number of private alleles (Fig. 5A). The larger Iranian population, created by merging an Iranian field population from 2005 with a second field population sampled from the same region in 2010, showed a similar trend (Fig. 5B). The larger sample size allowed ADZE to extrapolate to a higher final sample size, where the rarefaction curves appear to level off, with Iran having the highest level of private allelic richness in comparison to the other populations.
Sequence diversity for $P$. nodorum and Pat1 was also compared, but differences in sampling strategy and sample size between populations limited our ability to interpret these comparisons. Table 4 summarizes the average haplotype diversity by locus in three $P$. nodorum field populations with similar numbers of sequenced isolates. Fisher's exact tests did not detect significant differences in the proportion of private alleles at individual loci between field populations. Iran had a higher number of private alleles at the ITS locus and a higher overall number of private multilocus haplotypes. Fisher's exact test on the proportion of private multilocus haplotypes was significant at $p=0.036$. Overall, the distribution of genetic diversity shown in the sequence data is strikingly similar to the main findings obtained for the SSR markers (Fig. 5A and B). Average sequence diversity was comparable between Iran and Europe, but more private alleles were found in Iran. Average sequence diversity was generally lower in the South African population (Table 4). Table 4 also shows the rarefied species richness in a sub-sample size of 15 for each of the three field populations. The number of species was significantly higher in Iran and Denmark compared to South Africa and the difference between number of detected species between Iran and Denmark was also significant $(p<0.001)$.

Table 5 summarizes the number of multi-locus haplotypes and number of private multi-locus haplotypes found within regions 

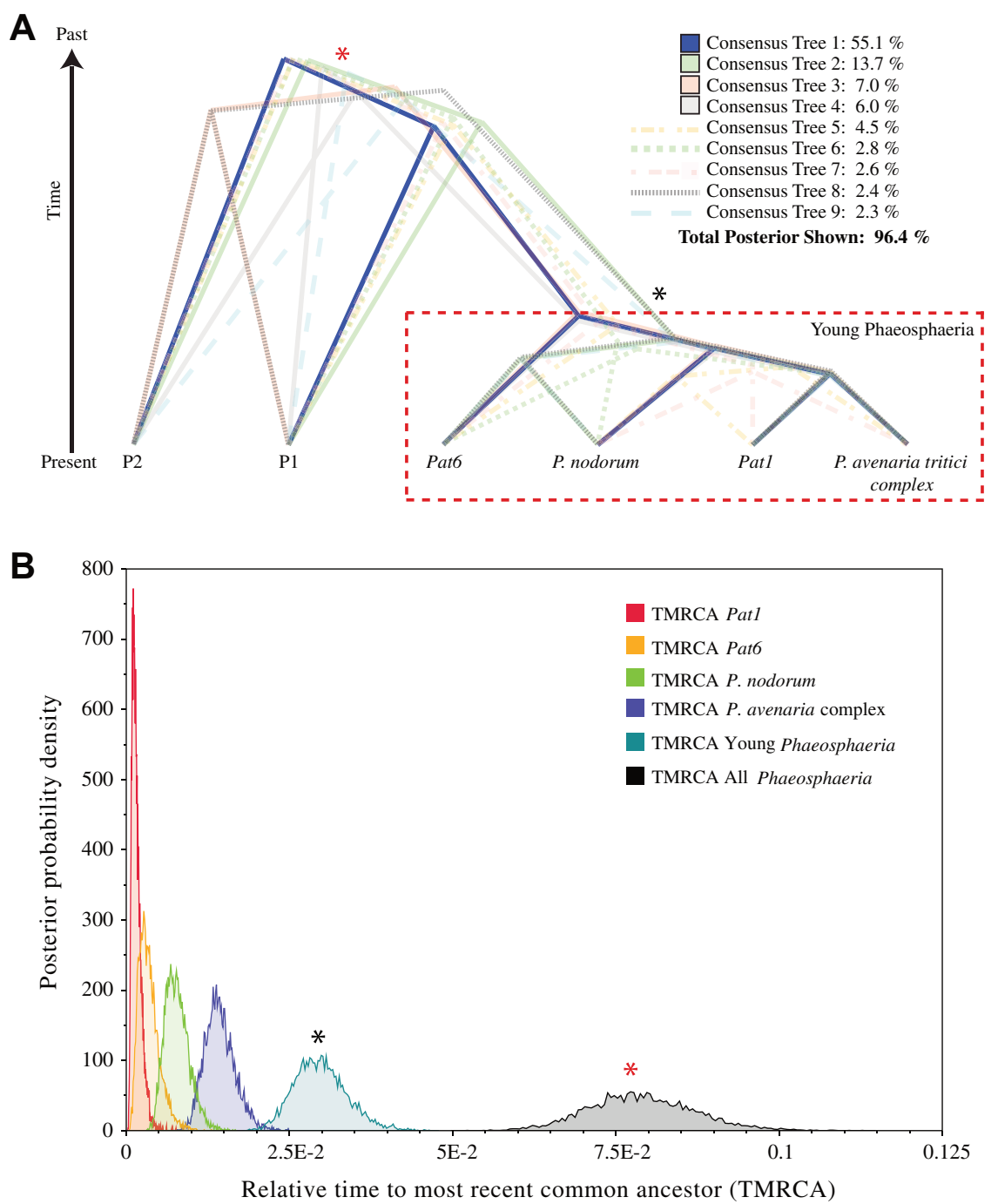

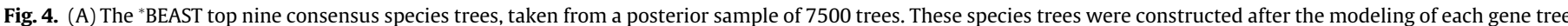

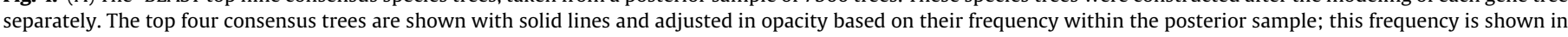

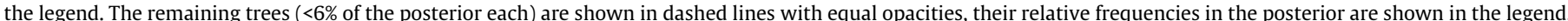

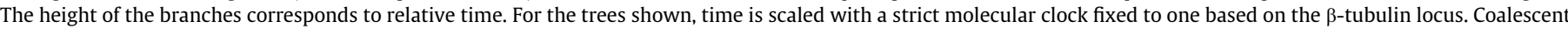

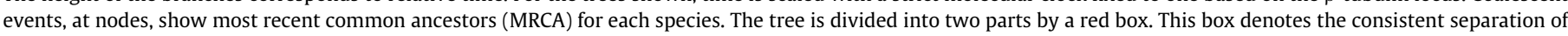

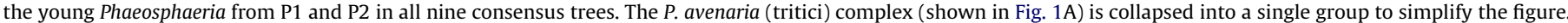

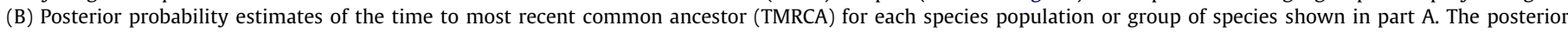

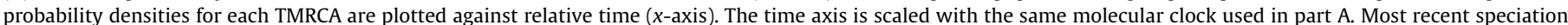

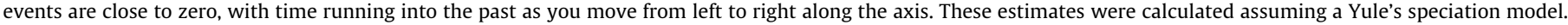
The black and red asterisks mark the time estimates that correspond with the nodes on the consensus trees depicted in part (A).

(not field populations). The P. nodorum collections from Iran, North America and Central Asia had considerably more private haplotypes than other regions (Table 5). Table 5 also shows the number of haplotypes, private haplotypes and proportion of private haplotypes for the Pat1 collections. The percentage of shared Pat1 haplotypes was relatively equal among regions (Table 5). Overall, $P$. nodorum had a higher number of total and private haplotypes when compared to Pat1 collected in the same region. To better illustrate the distribution of diversity in Pat1, a multi-locus haplotype network was constructed, excluding all hybrid isolates (Fig. 6). The number of multi-locus haplotypes was highest in Canada. The network shows several loops among haplotypes, indicating that recombination played a role in generating new multilocus haplotypes. This is consistent with the minimum number of recombination events shown in Table 3 . These results show all possible recombination routes to newly generated haplotypes, not the minimum number of recombination events.

\section{Discussion}

This study provides evidence from two independent neutral marker data sets that the origin of the wheat pathogen $P$. nodorum coincides with its host in the Fertile Crescent. We also clarify the relationships among wheat-infecting Phaeosphaeria species and several newly described relatives. Two of the nine species, $P$. nodorum and Pat1, are widely distributed in wheat fields globally, accounting for $\sim 85 \%$ of sampled isolates. Pat 1 was found almost exclusively in seed or ear collections. We hypothesize that this pattern indicates specialization of Pat1 to infect ears. Coalescent analysis identified a shared MRCA between $P$. nodorum and six additional species. This analysis indicates a rapid radiation of species from the shared ancestor, with three out of seven species described as wheat or oat pathogens. Coalescent analysis also revealed two new species closely related to the Phaeosphaeria spp. complex. Sequences from either P1 or P2 were divergent enough 

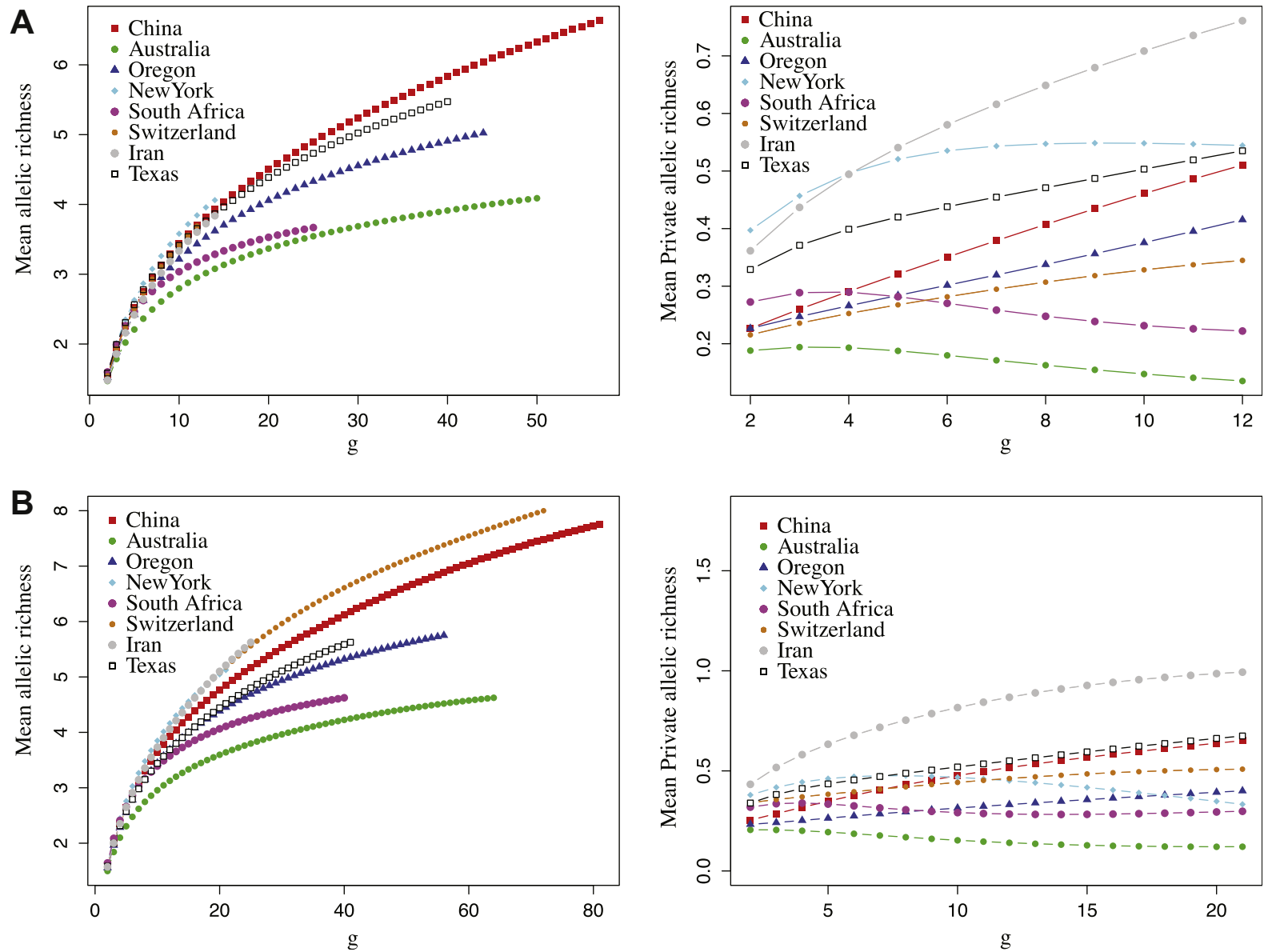

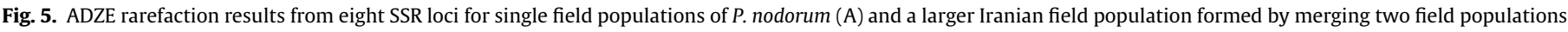

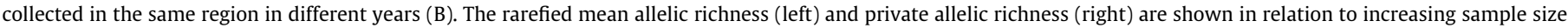
(g). Maximum g samples sizes are limited by the smallest population sample size.

to root the phylogeny of the remaining members of the Phaeosphaeria spp. complex.

\subsection{Differentiating Phaeosphaeria species}

Our phylogenetic analysis separated all clades with high posterior probability support, including non-synonymous differences between mating-type alleles (Appendix A.3). Non-synonymous changes between these idiomorphs are consistent with reproductive isolation between species. The coalescent analysis also successfully separated all isolates into distinct species groups with the highest possible posterior probability support (Appendix B.4). But the ancestral relationships among the species, in particular within the "young Phaeosphaeria" clade, remain unresolved (Fig. 4A). This is visible in Fig. 4A which shows the crossing of branches among species groups. We attribute this lack of resolution to incongruence in the ancestral nodes of gene trees for the three loci examined. All three loci, however, successfully separated P1 and P2 from the remaining Phaeosphaeria spp. Adding additional sequence loci or SNPs from genomic datasets will likely provide sufficient information to more precisely define the ancestral relationships among these Phaeosphaeria spp. The host range for each species is unknown, but $P$. nodorum was found on at least five different grass species in our collections. We postulate that the relatives of $P$. nodorum also retain the ability to colonize several grass hosts.

P. avenaria f. sp. tritici was originally described using 44 isolates collected from barley, rye, wheat, oats and other grasses (Shaw, 1957a). These isolates were found to be non-pathogenic on oats and were therefore given the formae specialis name tritici. Pathogenicity tests showed that about half of the isolates were weakly pathogenic on wheat, while the other half produced only traces of infection (Shaw, 1957a). Tests are currently underway to determine whether the recently discovered Pat species 3-6 are also pathogenic on wheat.

These results also significantly expand on earlier findings of a Phaeosphaeria species complex occurring on several plant hosts (Ueng et al., 1995, 1998; Malkus et al., 2005; Arkadiusz et al., 2006; Wang et al., 2007). We add three new P. avenaria f. sp. tritici (Pat) groups, isolated primarily from wild grasses, to the previously described Pat1 and Pat3 (Fig. 1). The Pat2 group described previously (Ueng et al., 1998) was not found in our collections. Our collection included eight isolates sampled from barley in North Dakota, which did not form a genetically distinct clade. These results indicate that $P$. nodorum barley biotypes are encompassed within the diversity observed within the $P$. nodorum species (Ueng et al., 1995). The two new, more distant species P1 and P2 were isolated from wheat ears in Iran.

P1 and P2 represent two un-described relatives of $P$. nodorum. We hypothesize that these species are relatives of $P$. nodorum that fall within the Phaeosphaeriaceae family described by Zhang et al. (2009). The closest known pathogenic relative outside of this family remains $P$. tritici-repentis, which belongs to the sister family Pleosporaceae. It is unclear whether P1 and P2 are widely distributed outside of the Fertile Crescent. BLAST search results of ITS sequences indicate that it may be possible to find these species 
Table 4

Sequence diversity by locus in Phaeosphaeria nodorum field populations and Phaeosphaeria avenaria tritici 1 collections of comparable sample size.

\begin{tabular}{|c|c|c|c|c|c|}
\hline \multirow{2}{*}{$\begin{array}{l}\text { P. nodorum } \\
\text { Locus }\end{array}$} & \multicolumn{5}{|l|}{ Allelic richness } \\
\hline & Population & $N$ & $N$ haplotypes & Private $H^{\mathrm{a}}$ & $N$ rare $H \pm \mathrm{sd}^{\mathrm{b}}$ \\
\hline \multirow[t]{3}{*}{$\beta$-Tubulin } & Iran ‘05 & 27 & 5 & 0 & $4.7 \pm 0.5$ \\
\hline & Denmark & 31 & 5 & 1 & $4.5 \pm 0.5$ \\
\hline & South Africa & 32 & 5 & 1 & $4.6 \pm 0.5$ \\
\hline \multirow[t]{3}{*}{$\beta$-Xylosidase } & Iran ‘05 & 27 & 5 & 0 & $3.2 \pm 0.7$ \\
\hline & Denmark & 31 & 6 & 1 & $5.5 \pm 0.6^{\mathrm{c}}$ \\
\hline & South Africa & 32 & 4 & 1 & $3.5 \pm 0.6$ \\
\hline \multirow[t]{3}{*}{ ITS } & Iran ‘05 & 27 & 6 & 3 & $3.9 \pm 0.6^{\mathrm{d}}$ \\
\hline & Denmark & 31 & 2 & 0 & $1.7 \pm 0.4$ \\
\hline & South Africa & 32 & 2 & 0 & $1.5 \pm 0.5$ \\
\hline \multirow[t]{7}{*}{ Multi-locus } & Iran ‘05 & 27 & 14 & $11^{\mathrm{e}}$ & $10.1 \pm 1.1^{\mathrm{f}}$ \\
\hline & Denmark & 31 & 14 & 6 & $9.9 \pm 1.1^{\mathrm{f}}$ \\
\hline & South Africa & 32 & 10 & 3 & $8.1 \pm 1.0$ \\
\hline & Species richness & & $N$ species & $N$ rare $S \pm \mathrm{sd}^{\mathrm{g}}$ & \\
\hline & Iran ‘05 & 42 & 4 & $3.5 \pm 0.6^{\mathrm{h}}$ & \\
\hline & Denmark & 37 & 2 & $2.0 \pm 0.2^{\mathrm{i}}$ & \\
\hline & South Africa & 32 & 1 & 1.0 & \\
\hline
\end{tabular}

a The number of private haplotypes observed in each field population. The proportion of private haplotypes was not different among populations at individual loci using Fisher's exact test for count data.

b The average and standard deviation of the total number of alleles sampled after rarefaction with a sample size of 15 .

c Statistically higher allelic richness in the Danish field population $p<0.001$.

d Statistically higher allelic richness in the Iranian field population $p<0.001$.

e Statistically higher proportion of private haplotypes in the Iranian population, $p=0.036$.

${ }^{\mathrm{f}}$ Statistically higher allelic richness in the Iranian and Danish fields compared to South Africa $p<0.001$.

g The average and standard deviation of the number of species sampled after rarefaction with a sample size of 15 .

h Statistically higher species richness was found in the Iranian field collection compared to both Danish and South African field populations, $T$ test $p<0.0001$.

i Statistically higher species richness was found in Denmark compared to the South African field population, $T$-test $p<0.0001$.

Table 5

Multi-locus haplotype diversity for Phaeosphaeria nodorum and Phaeosphaeria avenaria tritici 1 by population.

\begin{tabular}{|c|c|c|c|c|}
\hline Population & $N$ & $H^{\mathrm{a}}$ & Private $H$ & \% Private $H$ \\
\hline \multicolumn{5}{|c|}{ Phaeosphaeria nodorum multi-locus haplotype diversity by region } \\
\hline Asia & 8 & 5 & 0 & 0 \\
\hline South Africa & 32 & 10 & 3 & 30 \\
\hline Europe & 54 & 20 & 11 & 55 \\
\hline North America & 63 & 35 & 27 & 77 \\
\hline Central Asia & 40 & 32 & 25 & 78 \\
\hline Middle East & 29 & 16 & 13 & 81 \\
\hline Total & 226 & 93 & 77 & 83 \\
\hline \multicolumn{5}{|c|}{ Phaeosphaeria avenaria tritici 1 multi-locus haplotype diversity by region } \\
\hline Canada & 41 & 11 & 7 & 64 \\
\hline Central Asia & 5 & 2 & 1 & 50 \\
\hline Middle East & 19 & 5 & 3 & 60 \\
\hline North America & 8 & 5 & 2 & 40 \\
\hline Total & 73 & 18 & 13 & 72 \\
\hline
\end{tabular}

${ }^{\text {a }} H$ is the number of nucleotide haplotypes.

in Europe and China. Our P1 and P2 isolates were collected from wheat ears in Golestan Province in Iran. Additional collections made in the same province in 2010, in an attempt to re-sample these species, recovered only Pat 1 and $P$. nodorum from pycnidia on wheat ears.

The ITS region of P1 and P2 share at least 98\% sequence identity with several GenBank accessions compared to an average 89\% identity with $P$. nodorum. Several additional GenBank hits had higher sequence similarity to P1 and P2 than P. nodorum. Many of these fungi were collected during endophyte diversity screenings of soil, agricultural crops and trees. Without further sequences from these isolates it is not possible to correctly place them in the wheat-associated Phaeosphaeria spp. phylogeny presented in this manuscript. A more extensive sampling of grass-associated endophytes could reveal a wealth of currently un-named species that may be more closely related to $P$. nodorum than $\mathrm{P} 1$ and $\mathrm{P} 2$. The possible endophytic origins of $P$. nodorum are discussed below.

A third collection was made in 2011 from wild grass hosts, $A$. tauri and E. tauri, in the same region of Iran. This collection resulted in the discovery of Pat4 and Pat6. Despite differences in host of origin, the species from wild grasses were more closely related to $P$. nodorum than P1 and P2, with average ITS identity for Pat4 and Pat6 of $94 \%$ and $96 \%$ respectively. Pat 4 was close enough to $P$. avenaria and the other Pat lineages to be included in the $P$. avenaria f. sp. tritici complex. Pat6 split the phylogeny and was equidistant from the $P$. nodorum and Pat lineages, with an average nucleotide divergence of 103 nucleotides from $P$. nodorum and 94 nucleotides from Pat3 (Appendix A.2). The discovery of Pat4, Pat5 and Pat6 enriched the species tree, filling a large gap between $P$. nodorum and $P$. avenaria. This new phylogeny provides an excellent 


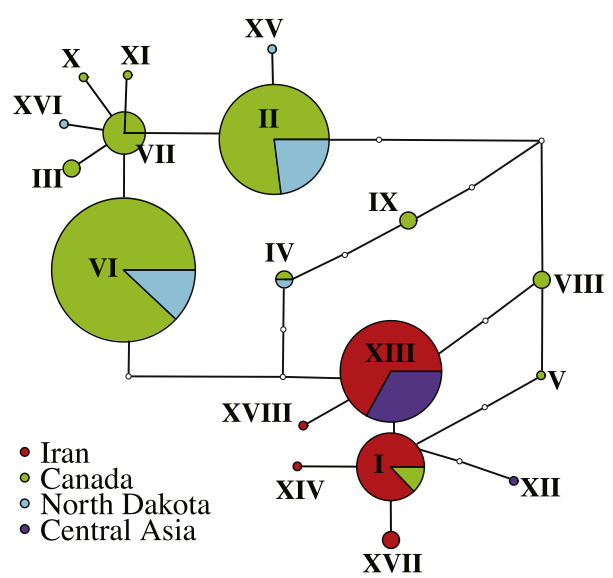

Fig. 6. Parsimony-based multi-locus haplotype network of Pat1 generated in TCS. The size of the circles corresponds to the number of isolates belonging to each haplotype. The haplotypes are divided into colors based on the population from which the isolates were collected. Missing haplotypes are denoted with white open circles. Each white open circle indicates a single point mutation. Loops are indicative of recombination. The network shows all possible recombination events, not the minimum number of events.

framework for placing additional species or enlarging the sample size of smaller groups.

\subsection{Evidence for specialization in Pat1 and hybridization with $P$. nodorum}

In contrast to the small number of isolates sampled for P1, P2 and Pat3-6, Pat1 was found in populations on different continents and accounted for $\sim 20 \%$ of the isolates in the total data set. The prevalence of Pat 1 in collections from Canada and Iran suggested that it would be useful to have a simple method to distinguish between $P$. nodorum and Pat1. We used our sequence data to develop a PCR-RFLP assay based on fixed species polymorphisms (Fig. 2) and validated it using more than 160 isolates. This test will be useful to determine if a collection contains mainly P. nodorum or Pat1 isolates, but it would not be able to detect the presence of hybrid isolates in the sample. Pat1 was isolated mainly from infected seeds or ears. We hypothesize that this correlation reflects specialization by Pat1 to infect ears, suggesting that Stagonospora leaf blotch is caused mainly by $P$. nodorum while Stagonospora glume blotch is caused by a combination of $P$. nodorum and Pat1. Further experiments will be needed to test this hypothesis.

It is unclear whether Pat1 is the homothallic species described more than 50 years ago (Shaw, 1957a). Malkus et al. (2005) described their Pat1 isolates as homothallic citing a previous publication by Ueng et al. (1998). While the 1998 publication by Ueng et al. does not explicitly deal with mating behavior, it cites two unpublished observations of perithecial formation in Pat 1 cultures started from single spores (G.M. Hoffmann and E. Arseniuk, unpublished data). Retention of sexual recombination after the loss of the MAT1-2 idiomorph has been observed in several Neurospora spp. (Lin and Heitman, 2007). The loops associated with the Pat1 multi-locus haplotype network (Fig. 6) indicate that recombination has occurred between loci. Tests for minimum number of recombination events also suggested that Pat1 has undergone at least one inter-genic recombination event. Combining these earlier observations with our findings, we consider it likely that the Pat 1 species described here is the same homothallic species first described by Shaw (1957a,b).

Our sample included 14 isolates that show evidence of hybridization between $P$. nodorum and Pat1. The finding of three different $P$. nodorum $\beta$-tubulin alleles in otherwise Pat1 isolates suggests that hybridization occurred independently at least three times. In fungi it remains unclear for how long interspecies fertility may persist after speciation (Giraud et al., 2008). Recent studies on the sister species of Microbotryum violaceum indicated that the two sister species diverged several hundred thousand years ago, but showed evidence for very recent gene flow through hybridization (Gladieux et al., 2010). Hybridization at the $\beta$-tubulin locus between sexual and asexual endophytic Clavicipitaceae species has also been reported (Moon et al., 2004; Schardl et al., 1994; Tsai et al., 1994).

We hypothesize that the hybrid strains result from sexual recombination between Pat1 and P. nodorum. Two Pat1 hybrid isolates possessed either a P. nodorum MAT1-1 allele or a MAT1-2 allele. Though two individuals is a small sample to support our hypothesis, earlier studies recognized hybrid isolates based on the presence of multiple gene copies within single isolates (Tsai et al., 1994. Schardl et al., 1994). We did not find multiple copies for any gene in any of the 14 hybrid isolates. Given that these 14 isolates represent $>4 \%$ of the 314 Pat $1, P$. nodorum and hybrid isolates included in the analysis, it appears that hybridization between these species may be relatively common. It is unclear whether these hybrid strains are aneuploids that contain duplicated chromosomes from each species, or are hybrids that have subsequently backcrossed with a parent species (introgressed). Genome-scale sequencing of these isolates will likely resolve many questions related to gene flow among Pat 1 and $P$. nodorum.

\subsection{Distribution of diversity for P. nodorum and other Phaeosphaeria species}

The collection from a wheat field in Iran provided us with an opportunity to compare the genetic diversity of $P$. nodorum at its hypothetical center of origin with other field populations. The Iranian population had a higher number of private alleles at the SSR loci, but average allelic richness was similar to other populations. Sequence data reflected the patterns observed for SSRs, with similar average allelic richness across populations, but the Iranian population had the largest number of private ITS alleles and the largest number of private multilocus haplotypes. Taken together these data are consistent with the hypothesis that the center of origin of $P$. nodorum is in the Fertile Crescent. Analyses of gene flow can provide additional support for a hypothesized center of origin by detecting ancient migration away from the center of diversity. But sufficient sample sizes are required for these analyses to consistently estimate levels and directions of gene flow among regions. Our attempts to analyze ancient migration using our small field collection of Iranian $P$. nodorum isolates were inconclusive.

Species richness offers additional support to the hypothesis of an origin in the Fertile Crescent (Table 4). Four related species, P1, P2, Pat1 and P. nodorum were collected from the same wheat field in Iran in 2005. Although our BLAST search results indicate that close relatives of P1 and P2 may be present outside of the Fertile Crescent, the isolation of all four species from a single wheat field indicates higher species richness in Iran compared to other wheat fields around the world. A new sample from the same region in 2010 recovered both Pat 1 and $P$. nodorum from infected ears. Pat 4 and Pat6 were collected from wild grasses in the same region in 2011.

We consider two possible scenarios to explain the observed pattern of global diversity. First, the Iranian populations may have diverged from other populations due to genetic drift as a result of geographical isolation. The Golestan Province of Iran is relatively isolated from other areas because it is surrounded by the Caspian Sea and the Alborz mountains. We consider this scenario highly unlikely because Iran experienced 1000s of years of international trade as a major hub on the Silk Road. Our earlier work indicated 
that $P$. nodorum populations around the world recombine regularly (McDonald et al., 1999; Sommerhalder et al., 2006; Stukenbrock et al., 2006) and our field experiments showed that airborne ascospores contribute significantly to epidemic development in Swiss wheat fields (Sommerhalder et al., 2010). Thus we believe that airborne ascospores are regularly carried over long distances, enabling significant gene flow over spatial scales of 100s-1000s of $\mathrm{km}$. To explain the observed global pattern of diversity, we hypothesize that the Iranian population represents an ancient pathogen population near the center of origin of the pathogen in the Fertile Crescent. We further hypothesize that recent international trade of infected wheat seed has enabled global dissemination of large, diverse populations of this fungus among the major wheat producing regions around the world, masking historical gene flow and lowering genetic differentiation between populations as we reported earlier (Stukenbrock et al., 2006). Larger population collections from the Fertile Crescent will be needed to conduct additional gene flow analyses that may identify a more precise origin of $P$. nodorum.

\subsection{Endophytic origins of the Phaeosphaeria spp. complex}

While our data suggests that the pathogen $P$. nodorum originated in the Fertile Crescent, we believe the Phaeosphaeria species complex likely originated in Eurasia long before the development of agriculture. The significant divergence found at highly conserved loci, including ITS and $\beta$-tubulin, indicate that this species complex is much older than Zymoseptoria tritici, another wheat pathogen thought to have emerged in the Fertile Crescent around 10,000 years ago (Stukenbrock et al., 2007). P. nodorum belongs to the Pleosporales, the largest order within the Dothideomycetes (Zhang et al., 2009). The Pleosporales are represented in the fossil record in the Eocene, giving a minimum age of 55-35 Ma (Mindell et al., 2007), but the order is thought to have emerged 280-175 Ma (Berbee and Taylor, 2010). Pollen records indicate that cool season grasses (including ancestors of wheat and oats) were widespread and abundant throughout Eurasia by the late Miocene (15-7 Ma). These grasses may have provided the first niches to be colonized by grass-associated saprophytic or endophytic fungi.

In a large phylogenetic study of the Pleosporales, $P$. nodorum and $P$. avenaria were placed in a clade associated mainly with endophytes and saprobes of terrestrial and water-associated grasses (Zhang et al., 2009). The prevalence of highly similar BLAST hits for P1 and P2 connected to endophyte studies is striking. In 250 BLAST hits of $90 \%$ similarity or higher, 61 (25\%) included the word endophyte in the GenBank accession file. Similarly 62 BLAST hits for P1 included the word endophyte and many of these accession numbers were the same between the two BLAST searches. The spatial distribution of BLAST hits with $>98 \%$ identity to P1 was limited to studies conducted in Eurasia, with the exception of an isolate collected from a maize plant in Ohio. For P2 two exact matches were found in air samples collected in Germany. The spatial distribution of BLAST hits became global at an identity of $97 \%$ or less for both species.

Phaeosphaeria spp. have long been recognized as common endophytes of grasses (Newell, 1996; Bergbauer and Newell, 1992). Several Phaeosphaeria spp. were described as beneficial, seed transmitted endophytes of the reed grass Phragmites australis (Ernst et al., 2003). Seed transmission is a common attribute of endophytic fungi (Clay and Schardl, 2002; Saikkonen et al., 2004) and is a noted feature of $P$. nodorum (Solomon et al., 2006). The Pat5 species described in this study is known to be avirulent on a collection of susceptible wheat cultivars (T. Friesen, unpublished data.). Pat5 was collected exclusively from wild grasses, including Agropyron cristatum (crested wheatgrass), Agropyron intermedium and Bromus inermis (smooth brome). All of these grass species are native to northeastern Europe and were imported into the United States for use as cold tolerant pasture grasses (www.plants. USDA.gov). P. avenaria and other unknown Phaeosphaeria spp. were recently isolated from asymptomatic leaf tissue in a diversity study examining fungal endophytes of Dactylis glomerata in Spain (Sánchez Márquez et al., 2007). Combining these findings with our collections from Iran, it appears that all of these Phaeosphaeria spp. have roots in Eurasian grasslands, leading us to hypothesize that this is the original source of the species complex.

We hypothesize that ancestral Phaeosphaeria spp. were present in the ancient Fertile Crescent living as endophytes or pathogens of wild grasses. The species we now call P. nodorum and Pat1 are domesticated pathogenic species that outcompeted their close relatives to colonize domesticated wheat. Because the closest relatives of $P$. nodorum and Pat 1 are not extinct, this collection of cryptic species provides us with an excellent opportunity to elucidate the molecular mechanisms that enabled P. nodorum and Pat1 to emerge as important pathogens on wheat.

\section{Acknowledgments}

The authors would like to thank all collectors who provided isolates or infected leaves. We also acknowledge the Genetic Diversity Center (GDC) in Zurich for providing excellent sequencing facilities. This project was funded by the ETH Zurich.

\section{Appendix A. Supplementary material}

Supplementary data associated with this article can be found, in the online version, at http://dx.doi.org/10.1016/j.fgb.2012.08.001.

\section{References}

Altekar, G., Dwarkadas, S., Huelsenbeck, J.P., Ronquist, F., 2004. Parallel metropolis coupled Markov chain Monte Carlo for Bayesian phylogenetic inference. Bioinformatics 20, 407-415.

Arkadiusz, M., Chang, P.-F., Zuzga, S.M., Chung, K.-R., Shao, J., Cunfer, B.M., Arseniuk E., Ueng, P.P., 2006. RNA polymerase II gene (RPB2) encoding the second largest protein subunit in Phaeosphaeria nodorum and P. avenaria. Mycol. Res. 110 $1152-1164$.

Arnold, E.A., 2007. Understanding the diversity of foliar endophytic fungi: progress, challenges, and frontiers. Fungal Biol. Rev. 21, 51-66.

Aylor, D.L., Price, E.W., Carbone, I., 2006. SNAP: combine and map modules for multi-locus population genetic analysis. Bioinformatics 22, 1399-1401.

Balter, M., 2007. Seeking agriculture's ancient roots. Science 316, 1830-1835.

Barrett, L.G., Kniskern, J.M., Bodenhausen, N., Zhang, W., Bergelson, J., 2009. Continua of specificity and virulence in plant host-pathogen interactions: causes and consequences. New Phytol. 183, 513-529.

Bennett, R., Yun, S., Lee, T., Turgeon, B., Arseniuk, E., Cunfer, B., Bergstrom, G., 2003 Identity and conservation of mating type genes in geographically diverse isolates of Phaeosphaeria nodorum. Fungal Genet. Biol. 40, 25-37.

Berbee, M., Taylor, J.W., 2010. Dating the molecular clock in fungi-how close are we? Fungal Biol. Rev. 24, 1-16.

Bergbauer, M., Newell, S.Y., 1992. Contribution to lignocellulose degradation and doc formation from a salt-marsh macrophyte by the ascomycete Phaeosphaeria spartinicola. FEMS Microbiol. Ecol. 86, 341-347.

Bouckaert, R.R., 2010. DensiTree: making sense of sets of phylogenetic trees. Bioinformatics 26, 1372-1373.

Cai, L., Giraud, T., Zhang, N., Bergerow, D., Cai, G., Shivas, R.G., 2011. The evolution of species concepts and species recognition criteria in plant pathogenic fungi. Fungal Div. 50, 121-133.

Clay, K., Schardl, C., 2002. Evolutionary origins and ecological consequences of endophyte symbiosis with grasses. Am. Nat. 160 (Suppl. 4), S99-S127.

Clement, M., Posada, D., Crandall, K., 2000. TCS: a computer program to estimate gene genealogies. Mol. Ecol. 9, 1657-1659.

Couch, B., Fudal, I., Lebrun, M., Tharreau, D., Valent, B., Van Kim, P., Nottéghem, J. Kohn, L., 2005. Origins of host-specific populations of the blast pathogen Magnaporthe oryzae in crop domestication with subsequent expansion of pandemic clones on rice and weeds of rice. Genetics 170, 613-630.

Cunfer, B., Ueng, P., 1999. Taxonomy and identification of Septoria and Stagonospora species on small-grain cereals. Ann. Rev. Phytopathol. 37, 267-284.

Drummond, A.J., Rambaut, A., 2007. BEAST: Bayesian evolutionary analysis by sampling trees. BMC Evol. Biol. 7, 214.

Ernst, M., Mendgen, K.W., Wirsel, S.G.R., 2003. Endophytic fungal mutualists: seedborne Stagonospora spp. enhance reed biomass production in axenic microcosms. Mol. Plant-Microbe Interact. 16, 580-587. 
Fisher, R.A., 1925. Statistical Methods for Research Workers, first ed. Oliver and Boyd, Edinburgh.

Giraud, T., Refregier, G., Le Gac, M., de Vienne, D.M., Hood, M.E., 2008. Speciation in fungi. Fungal Genet. Biol. 45, 791-802.

Gladieux, P., Zhang, X, Roldan-Ruiz, I. Caffier, V., Lerow, T., Devaux, M., Van Glabeke, S., Coart, E., Le Cam, B., 2010. Evolution of the population structure of Venturia inaequalis, the apple scab fungus, associated with the domestication of its host. Mol. Ecol. 19, 658-674.

Guindon, S., Gascuel, O., 2003. A simple, fast, and accurate algorithm to estimate large phylogenies by maximum likelihood. Syst. Biol. 52, 696-704.

Hane, J.K., Lowe, R.G.T., Solomon, P.S., Tan, K.-C., Schoch, C.L., Spatafora, J.W., Crous, P.W., Kodira, C., Birren, B.W., Galagan, J.E., Torriani, S.F.F., McDonald, B.A., Oliver, R.P., 2007. Dothideomycete-plant interactions illuminated by genome sequencing and EST analysis of the wheat pathogen Stagonospora nodorum. Plant Cell 19, 3347-3368.

Heled, J., Drummond, A.J., 2010. Bayesian inference of species trees from multilocus data. Mol. Biol. Evol. 27, 570-580.

Keller, S.M., McDermott, J.M., Pettway, R.E., Wolfe, M.S., McDonald, B.A., 1997. Gene flow and sexual reproduction in the wheat glume blotch pathogen Phaeosphaeria nodorum (Anamorph: Stagonospora nodorum). Phytopathology $87,353-358$

Kondrashov, A., 1986. Sympatric speciation: when is it possible? Biol. J. Linn. Soc. 27, 201-223.

Krupinsky, J.M., 1982. Comparative pathogenicity of Septoria nodorum isolated from Triticum aestivum and Agropyron species. Phytopathology 72, 660-661.

Librado, P., Rozas, J., 2009. DnaSP v5: a software for comprehensive analysis of DNA polymorphism data. Bioinformatics $25,1451-1452$.

Lin X., Heitman, J., 2007. Mechanisms of homothallism in fungi and transitions between heterothallism and homothallism. In: Heitman J., Kronstad, J.W., Taylor, J.W., Casselton, L.A. (Eds.), Sex in Fungi. ASM Press, Washington, DC, USA, pp. 35-56.

Malkus, A., Reszka, E., Chang, C.-J., Arseniuk, E., Chang, P.-F.L., Ueng, P.P., 2005 Sequence diversity of $\beta$-tubulin (tubA) gene in Phaeosphaeria nodorum and $P$. avenaria. FEMS Microbiol. Lett. 249, 49-56.

Martin, S.I., Cooke, B.M., 1979. Effect of wheat and barley hosts on pathogenicity and cultural behaviour of barley and wheat isolates of Septoria nodorum. Trans. Brit. Mycol. Soc. 72, 219-224.

McDonald, B.A., Martinez, J.P., 1990. Restriction fragment length polymorphisms in Septoria tritici occur at a high frequency. Curr. Genet. 17, 133-138.

McDonald, B.A., Zhan, J., Yarden, O., Hogan, K., Garton, J., Pettway, R.E., 1999. The population genetics of Mycosphaerella graminicola and Phaeosphaeria nodorum. In: Lucas, J.A., Bowyer, P., Anderson, H.M. (Eds.), Septoria on Cereals: A Study of Pathosystems. CAB International, Wallingford, UK, pp. 44-69.

Mindell, R.A., Stockey, R.A., Beard, G., Currah, R.S., 2007. Margaretbarromyces dictyosporus gen. sp. nov.: a permineralized corticolous ascomycete from the Eocene of Vancouver Island, British Columbia. Mycol. Res. 111, 680-684.

Moon, C.D., Craven, K.D., Leuchtmann, A., Clement, S.L., Schardl, C.L., 2004 Prevalence of interspecific hybrids amongst asexual fungal endophytes of grasses. Mol. Ecol. 13, 1455-1467.

Newell, S.Y., 1996. Established and potential impacts of eukaryotic mycelia decomposers in marine/terrestrial ecotones. J. Exp. Mar. Biol. Ecol. 200, 187206.

Osbourn, A., Scott, P., Caten, C., 1986. The effects of host passaging on the adaptation of Septoria nodorum to wheat or barley. Plant Pathol. 35, 135-145.

Paradis, E., 2010. Pegas: an R package for population genetics with an integratedmodular approach. Bioinformatics 26, 419-420.

Posada, D., 2008. JModelTest: phylogenetic model averaging. Mol. Biol. Evol. 25 $1253-1256$.

Price, E.W., Carbone, I., 2005. SNAP: workbench management tool for evolutionary population genetic analysis. Bioinformatics 21, 402-404.

Quaedvlieg, W., Kema, G.H.J., Groenewald, J.Z., Verkley, G.J.M., Seifbarghi, S., Razavi, M., Mirzadi Gohari, A., Mehrabi, R., Crous, P.W., 2011. Zymoseptoria gen. nov.: a new genus to accommodate Septoria-like species occurring on graminicolous hosts. Persoonia 26, 57-69.

Reszka, E., Chung, K.R., Tekauz, A., Malkus, A., Arseniuk, E., Krupinsky, J.M. Tsang, H., Ueng, P.P., 2005. Presence of beta-glucosidase (bgl1) gene in Phaeosphaeria nodorum and Phaeosphaeria avenaria f.sp. triticea. Can. J. Bot 83, 1001-1014.

Ronquist, F., Huelsenbeck, J.P., 2003. MrBayes 3: Bayesian phylogenetic inference under mixed models. Bioinformatics 19, 1572-1574.

Rozas, J., Rozas, R., 1995. DnaSP, DNA sequence polymorphism: an interactive program for estimating population genetics parameters from DNA sequence data. Comput. Appl. Biosci. 11, 621-625.

Saikkonen, K., Wali, P., Helander, M., Faeth, S., 2004. Evolution of endophyte-plant symbioses. Trends Plant Sci. 9, 275-280.

Sánchez Márquez, S., Bills, G.F., Zabalgogeazcoa, I., 2007. The endophytic mycobiota of the grass Dactylis glomerata. Fungal Div. 27, 171-195.
Saunders, M., Kohn, L., 2009. Evidence for alteration of fungal endophyte community assembly by host defense compounds. New Phytol. 182, 229-238.

Saunders, M., Kohn, L., 2010. Exploring the evolutionary ecology of fungal endophytes in agricultural systems: using functional traits to reveal mechanisms in community processes. Evol. Appl. 3, 525-537.

Schardl, C.L., Leuchtmann, A., Tsai, H.F., Collett, M.A., Watt, D.M., Scott, B., 1994. Origin of a fungal symbiont of perennial ryegrass by interspecific hybridization of a mutualist with the ryegrass choke pathogen Epichloë typhina. Genetics 136, 1307-1317.

Schulz, B., Boyle, C., 2005. The endophytic continuum. Mycol. Res. 109, 661-686.

Shaw, D., 1957a. Studies on Leptosphaeria avenaria f. sp. triticea on cereals and grasses. Can. J. Bot. 35, 113-118.

Shaw, D.E., 1957b. Studies on Leptosphaeria avenaria f. sp. avenaria. Can. J. Bot. 35 , 97-112.

Simberloff, D., 1972. Properties of the rarefaction diversity measurement. Am. Nat 106, 414-418.

Solomon, P.S., Lowe, R.G.T., Tan, K.-C., Waters, O.D.C., Oliver, R.P., 2006. Stagonospora nodorum: cause of Stagonospora nodorum blotch of wheat. Mol. Plant Pathol. 7, $147-156$.

Sommerhalder, R.J., McDonald, B.A., Zhan, J., 2006. The frequencies and spatial distribution of mating types in Stagonospora nodorum are consistent with recurring sexual reproduction. Phytopathology 96, 234-239.

Sommerhalder, R.J., McDonald, B.A., Mascher, F., Zhan, J., 2010. Sexual recombinants make a significant contribution to epidemics caused by the wheat pathogen Phaeosphaeria nodorum. Phytopathology 100, 855-862.

Stamatakis, A., 2006. RAxML-VI-HPC: maximum likelihood-based phylogenetic analyses with thousands of taxa and mixed models. Bioinformatics 22, 26882690.

Stamatakis, A., Hoover, P., Rougemont, J., 2008. A rapid bootstrap algorithm for the RAxML web Servers. Syst. Biol. 57, 758-771.

Stukenbrock, E.H., Banke, S., Zala, M., McDonald, B.A., Oliver, R., 2005. Isolation and characterization of EST-derived microsatellite loci from the fungal wheat pathogen Phaeosphaeria nodorum. Mol. Ecol. Notes 5, 931-933.

Stukenbrock, E.H., Banke, S., Javan-Nikkhah, M., McDonald, B.A., 2007. Origin and domestication of the fungal wheat pathogen Mycosphaerella graminicola via sympatric speciation. Mol. Biol. Evol. 24, 398-411.

Stukenbrock, E.H., Banke, S., McDonald, B.A., 2006. Global migration patterns in the fungal wheat pathogen Phaeosphaeria nodorum. Mol. Ecol. 15, 2895-2904

Stukenbrock, E.H., McDonald, B.A., 2008. The origins of plant pathogens in agroecosystems. Annu. Rev. Phytopathol. 46, 75-100.

Stukenbrock, E.H., Bataillon, T., Dutheil, J.Y., Hansen, T.T., Li, R., Zala, M., McDonald, B.A., Wang, J., Schierup, M.H., 2011. The making of a new pathogen: Insights from comparative population genomics of the domesticated wheat pathogen Mycosphaerella graminicola and its wild sister species. Genome Res. 21, 21572166

Stukenbrock, E.H., Quaedvlieg, W., Javan-Nikhah, M., Zala, M., Crous, P.W., McDonald, B.A., 2012. Zymoseptoria ardabilia and $Z$ pseudotritici, two progenitor species of the Septoria tritici leaf blotch fungus $Z$. tritici (synonym: Mycosphaerella graminicola). Mycologia http://dx.doi.org/10.3852/11-374.

Szpiech, Z.A., Jakobsson, M., Rosenberg, N.A., 2008. ADZE: a rarefaction approach for counting alleles private to combinations of populations. Bioinformatics 24 2498-2504.

Taylor, J.W., Jacobson, D.J., Kroken, S., Kasuga, T., Geiser, D.M., Hibbett, D.S., Fisher, M.C., 2000. Phylogenetic species recognition and species concepts in fungi. Fungal Genet. Biol. 31, 21-32.

Tsai, H.F., Liu, J.S., Staben, C., Christensen, M.J., Latch, G.C.M., Siegel, M.R., Schardl, C.L., 1994. Evolutionary diversification of fungal endophytes of tall fescue grass by hybridization with Epichloë species. PNAS 91, 2542-2546.

Ueng, P.P., Chen, W., 1994. Genetic differentiation between Phaeosphaeria nodorum and $P$. avenaria using restriction fragment length polymorphisms. Phytopathology 84, 800-806.

Ueng, P., Cunfer, B., Alano, A., Youmans, J., Chen, W., 1995. Correlation between molecular and biological characters in identifying the wheat and barley biotypes of Stagonospora nodorum. Phytopathology 85, 44-52.

Ueng, P., Subramaniam, K., Chen, W., Arseniuk, E., Wang, L., Cheung, A., Hoffmann, G., Bergstrom, G., 1998. Intraspecific genetic variation of Stagonospora avenae and its differentiation from S. nodorum. Mycol. Res. 102, 607-614.

Ueng, P.P., Dai, Q., Cui, K.-R., Czembor, P.C., Cunfer, B.M., Tsang, H., Arseniuk, E., Bergstrom, G.C., 2003. Sequence diversity of mating-type genes in Phaeosphaeria avenaria. Curr. Genet. 43, 121-130.

Wang, C.-L., Arkadiusz, M., Zuzga, S.M., Chang, P.-F.L., Cunfer, B.M., Arseniuk, E. Ueng, P.P., 2007. Diversity of the trifunctional histidine biosynthesis gene (his) in cereal Phaeosphaeria species. Genome 50, 595-609.

Zhang, Y., Schoch, C.L., Fournier, J., Crous, P.W., de Gruyter, J., Woudenberg, J.H.C., Hirayama, K., Tanaka, K., Pointing, S.B., Spatafora, J.W., Hyde, K.D., 2009. Multilocus phylogeny of Pleosporales: a taxonomic, ecological and evolutionary reevaluation. Stud. Mycol. 64, 85-102S5. 